\title{
Characterization of acetylcholinesterase from elm left beetle, Xanthogaleruca luteola and QSAR of temephos derivatives against its activity
}

Mahboobeh Sharifi $^{\mathrm{a}}$, Mohammad Ghadamyari ${ }^{\mathrm{a} *}$, Khodayar Gholivand $^{\mathrm{b}}$, Ali Asghar Ebrahimi Valmoozi ${ }^{\mathrm{b}}$, Reza H. Sajedi ${ }^{c}$

${ }^{a}$ Department of Plant Protection, Faculty of Agricultural Sciences, University of Guilan, Rasht, Iran

${ }^{\mathrm{b}}$ Department of Chemistry, Tarbiat Modares University, Tehran, Iran

${ }^{\mathrm{c}}$ Department of Biochemistry, Tarbiat Modares University, Tehran, Iran

*Corresponding author (E-mail: ghadamyari@guilan.ac.ir or mghadamyari@gmail.com; Tel.: 0098-131-6690009 (office); Fax: 0098-131-6690281) 


\title{
Characterization of acetylcholinesterase from elm left beetle, Xanthogaleruca luteola and QSAR of temephos derivatives against its activity
}

\begin{abstract}
Absrtact
Insect acetylcholinesterase (AChE) is the principal target for organophosphate (OP) and carbamate (CB) insecticides. In this research, an AChE from third instar larvae of elm left beetle, Xanthogaleruca luteola was purified by affinity chromatography. The enzyme was purified 75.29-fold with a total yield of $8.51 \%$. As shown on denaturing SDS-PAGE, the molecular mass of purified AChE was $70 \mathrm{kDa}$. The enzyme demonstrated maximum activity at $\mathrm{pH} 7$ and $35^{\circ} \mathrm{C}$. Furthermore, a series of temephos (Tem) derivatives with the general structure of $\mathrm{P}(\mathrm{O})-\mathrm{X}-\mathrm{P}(\mathrm{O})$ (1-44) were prepared, synthesized and characterized by ${ }^{31} \mathrm{P},{ }^{13} \mathrm{C},{ }^{1} \mathrm{H}$ NMR and FT-IR spectral techniques. The toxicity of 36 new Tem derivatives was screened on the third instar larvae and the compound compound 1,2 cyclohexane-N,N'-bis(N,N'-piperidine phosphoramidate) exhibited the highest insecticidal potential. The method of kinetic analysis is applied in order to obtain the maximum velocity $\left(V_{\max }\right)$, the Michaelis constant $\left(K_{\mathrm{m}}\right)$ and the parameters characterizing the inhibition type for inhibitors with $>75 \%$ mortality in preliminary bioassay. The inhibition mechanism was mixed and inhibitory constant $\left(K_{i}\right)$ was calculated as $4.70 \mu \mathrm{M}^{-1} \mathrm{~min}^{-1}$ for this compound. Quantitative structure-activity relationship (QSAR) equations of these compounds indicated that the electron orbital energy has major effect on insecticidal properties.
\end{abstract}

Key words: QSAR, Biochemical properties, Acetylcholinesterase, Organophosphate

\section{Introduction}


AChE (EC 3.1.1.7) is a hydrolyzing enzyme that plays a vital role in cholinergic neurotransmission. This enzyme hydrolyses the neurotransmitter, acetylcholine (ACh) into choline and acetate [1]. AChE is the principal target of organophosphate (OP) and carbamate (CB) pesticides. These pesticides irreversibly bind to the serine amino acid in the active site of AChE. This inhibition results in sustained muscle impulses, insect convulsion, and even death [2]. Several biochemical and molecular studies have been focused to AChE properties in insect as regards the role of AChE in neurotransmission and its insensitivity to insecticides So far, AChEs have been purified and characterized from some insect species including, Diabrotica virgifera [3], Aphis gossypii [4], Spodoptera frugiperda [5], Bactrocera dorsalis [6] and Bombyx mandarina [7]. Crude extracts from insect homogenization contain substantial amounts of contaminants and general esterases. These factors can affect the activity and biochemical properties of AChE in biochemical assay and one of the remedy for this problem is purification of AChE by chromatography techniques.

Due to the widespread and extensive use of pesticides in agriculture and health, its resistance has been significantly increased [2]. Therefore, by considering the resistance problem, numerous researches have focused on the need for safer, environmentally friendly pesticides and pesticides with novel mode of action. A rational method for achieving this objective is the application of QSAR (Quantitative Structure-Activity Relationship) models for the rapid prediction, saving costs and time for discovery of compound with new insecticidal activity. The QSAR is an appropriate tool in insecticide discovery to the extent that a mathematical equation was used to link the biological activity with a wide variety of physical or chemical parameters. So far, QSAR models have been successfully used for finding new compounds with pesticide activity [8; 9] 
and some QSAR studies have been conducted for the screening of new organophosphates and carbamates $[10 ; 11]$.

In this paper, an AChE from the elm leaf beetle was purified and its biochemical properties were characterized because of the importance of AChE inhibition by phosphoroamide (PHA) derivatives. . Furthermore, the median inhibitory concentration $\left(\mathrm{I}_{\mathbf{5 0}}\right)$ and mechanism of inhibition of these compounds on AChE were determined after the screening of the PHA derivatives on third instar larvae. In addition, the relationship between their physico-chemical characteristics and insecticidal effect, as biological activity, were presented with equation.

\section{Materials and Methods}

\subsection{Insect rearing}

Eggs and larvae of $X$. luteola were collected from the elm tree in pesticide-free trees in the University of Guilan, Rasht, Iran. Insect colonies were reared in the laboratory conditions at $25 \pm$ $2{ }^{\circ} \mathrm{C} ; 16: 8 \mathrm{~h}(\mathrm{~L}: \mathrm{D}) ; 75 \pm 10 \% \mathrm{RH}$ in transparent plastic jars $10 \times 20 \mathrm{~cm}[12]$.

\subsection{Screening test}

The synchronized third instars larvae were used in screening test. At the first, the concentrations of 5000 and $2500 \mathrm{mg} / \mathrm{ml}$ of PHA compounds, dissolved in DMSO: water (1:4), were prepared. Third instars larvae were immersed in solution made for 15 seconds. The treated insects were transferred on filter paper to drain. Control insects were dipped in DMSO: water (1:4). The treated insects were held in the laboratory conditions at $25 \pm 2{ }^{\circ} \mathrm{C} ; 16: 8 \mathrm{~h}(\mathrm{~L}: \mathrm{D}) ; 75 \pm 10 \% \mathrm{RH}$ in transparent plastic jars $10 \times 20 \mathrm{~cm}$ with elm leaf as food. Mortality was counted after $24 \mathrm{~h}$ [13]. The compounds with mortalities higher than $75 \%$ were chosen and bioassayed again on third instar larvae.

\subsection{Bioassays}


The bioassay was conducted on the compounds with more than $75 \%$ mortality in the second concentration (i.e. $2500 \mathrm{mg} / \mathrm{l}$ ) of screening test. The bioassay was carried out with concentrations of $310,650,1250$ and $2500 \mathrm{mg} / \mathrm{l}$ and each third instar larvae were dipped in solution of different concentrations for $15 \mathrm{~s}$. After that the insects drained on a filter paper and the treated insects were transferred to transparent plastic jars $10 \times 20 \mathrm{~cm}$ containing fresh elm leaves. This experiment was repeated 5 times for each treatment and 10 larvae of the same age were used in each replicate. Mortality was recorded after $24 \mathrm{~h}$ and the $\mathrm{LC}_{50} \mathrm{~S}$ and their confidence limits were estimated using POLO-PC software [14].

\subsection{Sample preparation and enzyme assays}

The larvae alive after treatment with compounds 19, 30, 32 and 50 were homogenized in 200 $\mu 1$ phosphate buffer $\mathrm{pH} 7.0$ containing triton $\mathrm{X}-100$. The homogenates were centrifuged at 12000 $\times g$ for 10 minutes at $4{ }^{\circ} \mathrm{C}$. The supernatants were used as the enzyme source. AChE activity was determined according to Ellman et al. method [15] using acetylthiocholine iodide as substarte. Forty $\mu \mathrm{l}$ of supernatant was added to a tube containing $140 \mu \mathrm{l}$ of phosphate buffer ( $20 \mathrm{mM}$; pH 7), $40 \mu$ substrate (acetylthiochoiline iodide), $20 \mu \mathrm{LTNB}$. Increase in absorbance was recorded at $415 \mathrm{~nm}$ using a microplate reader (Awareness technology Stat fax $3200^{\circledR}$ ). The enzyme velocity was converted to unit activity using the molar extinction coefficient of $13.6 \mathrm{mM} \mathrm{cm}^{-1}$ for 5 thio-2-nitrobenzoate formed during the assay at $412 \mathrm{~nm}$. AChE specific activity was expressed as units per mg of protein after measurement of protein by Bradford (1976) method [16], using bovine serum albumin (BSA) as standard. For esterase enzyme assay, $12.5 \mu 1$ of supernatant was mixed with $50 \mu \mathrm{l}$ of substrates (alpha-naphthyl acetate (a-NA) or beta-naphthyl acetate ( $\beta$-NA)), $112.5 \mu \mathrm{l}$ of the phosphate buffer and $50 \mu \mathrm{l}$ of Fast Blue RR salt and the naphthol production was 
monitored by measuring absorbance at 450 and $540 \mathrm{~nm}$ for a-NA and $\beta-\mathrm{NA}$, respectively, using a microplate reader (Awareness Technology Inc, Stat Fax 3200®) as a kinetic mode [17].

\subsection{Procedure for the synthesis of compounds}

The synthesized method of compounds 12-24 and compounds 25-44 was presented to the references [18] and [19], respectively.

\subsubsection{General synthesis}

Synthesis of bis phosphorus amido chalcogenides ligands with skeleton $\mathrm{P}(\mathrm{O})$-NH-P $(\mathrm{O})$ :

The compound $\left(\mathrm{C}_{6} \mathrm{H}_{5} \mathrm{O}\right) 2 \mathrm{P}(\mathrm{O}) \mathrm{NH}(1 \mathrm{mmol})$ is added to a solution of $30 \mathrm{ml}$ dry carbon tetrachloride with solvent $(1 \mathrm{mmol})$ of phosphorous penta chloride gas. The reaction mixture is ref-

lux for $18 \mathrm{~h}$. After cooling the product reflux, $(1 \mathrm{mmol})$ of formic acid is added to it. After $2 \mathrm{~h}$ of mixing of the solution to air at room temperature, the solvent was thrown and white precipitate of $30 \mathrm{ml}$ carbon tetrachloride washing net $\left(\mathrm{C}_{6} \mathrm{H}_{5} \mathrm{O}\right) 2 \mathrm{P}(\mathrm{O}) \mathrm{NHP}(\mathrm{O}) \mathrm{Cl}$ was separated. In the next step, $(1 \mathrm{mmol})$ of intermediate 2 acetonitrile or tetrahydrofuran amine $(4 \mathrm{mmol})$ is added to $10 \mathrm{~mL}$ of solvent and was stirred for 8 hours at -5 to $-8^{\circ} \mathrm{C}$. Then mixing the solution to air deposition and thrown solvent and by washing with water, it was purified (Scheme 1) 


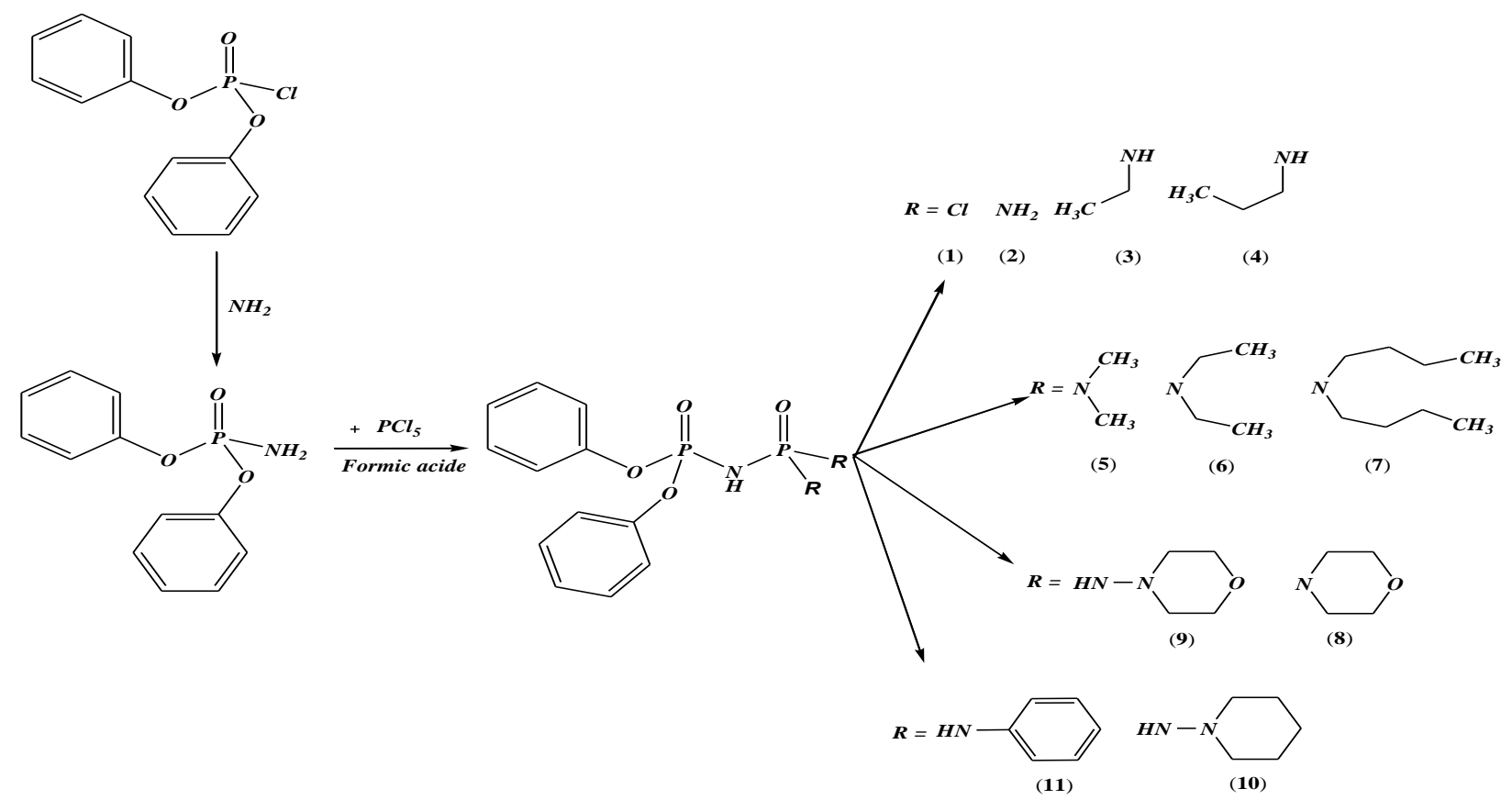

Scheme 1.

\section{$\left(\mathrm{C}_{6} \mathrm{H}_{5} \mathrm{O}\right)_{2} \mathrm{P}(\mathrm{O}) \mathrm{NHP}(\mathrm{O}) \mathrm{Cl}_{2}(\mathbf{1})$}

Powder sample; m.p. $163-165{ }^{\circ} \mathrm{C} .{ }^{1} \mathrm{H}$ NMR $\left(500.13 \mathrm{MHz}\right.$, d6-DMSO, $\left.25^{\circ} \mathrm{C}, \mathrm{TMS}\right) ; \delta=7.18$ (t, 2 H, para-phenyl), 7.24 (d, 4 H, ortho-phenyl), 7.37 (t, $4 \mathrm{H}$, meta-phenyl), 8.33 (b, $1 \mathrm{H}, \mathrm{NH}$ ) ppm. ${ }^{13} \mathrm{C}$ NMR $\left(125.77 \mathrm{MHz}, \mathrm{d} 6-\mathrm{DMSO}, 25^{\circ} \mathrm{C}\right.$, TMS $) ; \delta=120.41\left(\mathrm{~d},{ }^{3} J_{\mathrm{PC}}=4.8 \mathrm{~Hz}, 4 \mathrm{C}\right.$, orthophenyl), 124.72 (s, 2 C, para-phenyl), 129.45 (s, 4 C, meta-phenyl), 150.56 (d, ${ }^{2} J_{\mathrm{PC}}=6.7 \mathrm{~Hz}, 2$ C, ipso-phenyl) ppm. ${ }^{31} \mathrm{P}\left\{{ }^{1} \mathrm{H}\right\}$ and ${ }^{31} \mathrm{P}$ NMR (202.45 MHz, d6-DMSO, $25^{\circ} \mathrm{C}, \mathrm{H}_{3} \mathrm{PO}_{4}$ external); $\delta=-3.87\left(\mathrm{~d},{ }^{2} J_{\mathrm{PP}}=9.3 \mathrm{~Hz}\right),-7.10\left(\mathrm{~d},{ }^{2} J_{\mathrm{PP}}=9.6 \mathrm{~Hz}\right) \mathrm{ppm} . \mathrm{IR}(\mathrm{KBr}): \widetilde{v}=2940.5(\mathrm{~N}-\mathrm{H}), 2720.1$ (s), $1595.3(\mathrm{~s}), 1491.7$ (s), $1391.8(\mathrm{~s}), 1256.7(\mathrm{P}=\mathrm{O}), 1193.4(\mathrm{P}=\mathrm{O}), 1008.5(\mathrm{P}-\mathrm{O}), 762.8(\mathrm{P}-\mathrm{N})$, $497.3(\mathrm{P}-\mathrm{Cl})$.

\section{$\left(\mathrm{C}_{6} \mathrm{H}_{5} \mathrm{O}\right)_{2} \mathrm{P}(\mathrm{O}) \mathrm{NHP}(\mathrm{O})\left(\mathrm{NH}_{2}\right)_{2}(2)$}

powder sample; ${ }^{1} \mathrm{H}$ NMR $\left(250.13 \mathrm{MHz}, \mathrm{d} 6-\mathrm{DMSO}, 25^{\circ} \mathrm{C}, \mathrm{TMS}\right) ; \delta=5.53\left(\mathrm{~m}, 4 \mathrm{H}, \mathrm{NH}_{2}\right.$ ), 7.19 (t, 2 H, para-phenyl), 7.27 (d, 4 H, ortho-phenyl), 7.42 (t, 4 H, meta-phenyl), 8.33 (b, $1 \mathrm{H}$, 
NH) ppm. ${ }^{13} \mathrm{C}$ NMR $\left(62.89 \mathrm{MHz}, \mathrm{d} 6-\mathrm{DMSO}, 25^{\circ} \mathrm{C}, \mathrm{TMS}\right) ; \delta=120.82\left(\mathrm{~d},{ }^{3} J_{\mathrm{PC}}=7.8 \mathrm{~Hz}, 4 \mathrm{C}\right.$, ortho-phenyl), 125.13 (s, 2 C, para-phenyl), 129.79 (s, 4 C, meta-phenyl), 151.00 (d, 2 C, ipsophenyl) ppm. ${ }^{31} \mathrm{P}\left\{{ }^{1} \mathrm{H}\right\}$ and ${ }^{31} \mathrm{P}$ NMR $\left(101.25 \mathrm{MHz}, \mathrm{d} 6-\mathrm{DMSO}, 25^{\circ} \mathrm{C}, \mathrm{H}_{3} \mathrm{PO}_{4}\right.$ external); $\delta=-7.33$ $\left(\mathrm{d},{ }^{2} J_{\mathrm{PP}}=9.4 \mathrm{~Hz}\right),-9.35\left(\mathrm{~d},{ }^{2} J_{\mathrm{PP}}=9.8 \mathrm{~Hz}\right) \mathrm{ppm} . \mathrm{IR}(\mathrm{KBr}): \tilde{v}=3483.7(\mathrm{~N}-\mathrm{H}), 3185.1(\mathrm{~N}-\mathrm{H})$, 3063.4 (s), 1592.4 (s), 1488.6 (s), 1332.3 (s), $1219.6(\mathrm{P}=\mathrm{O}), 1149.1(\mathrm{P}=\mathrm{O}), 1027.0(\mathrm{P}-\mathrm{O}), 932.1$ $(\mathrm{P}-\mathrm{N})$.

\section{$\left(\mathrm{C}_{6} \mathrm{H}_{5} \mathrm{O}\right)_{2} \mathrm{P}(\mathrm{O}) \mathrm{NHP}(\mathrm{O})\left(\mathrm{NHC}_{2} \mathrm{H}_{5}\right)_{2}(3)$}

powder sample; m.p. $143-145{ }^{\circ} \mathrm{C} .{ }^{1} \mathrm{H}$ NMR $\left(250.13 \mathrm{MHz}, \mathrm{d} 6-\mathrm{DMSO}, 25^{\circ} \mathrm{C}\right.$, TMS $) ; \delta=1.21-$ $1.23\left(\mathrm{~m}, 6 \mathrm{H}, \mathrm{NHC}_{2} \mathrm{H}_{5}\right), 2.73\left(\mathrm{~m}, 4 \mathrm{H}, \mathrm{NHC}_{2} \mathrm{H}_{5}\right), 4.99(\mathrm{~m}, 4 \mathrm{H}, \mathrm{NH}), 7.15(\mathrm{t}, 2 \mathrm{H}$, para-phenyl), 7.29 (d, 4 H, ortho-phenyl), 7.32 (t, 4 H, meta-phenyl), 8.30 (b, $1 \mathrm{H}, \mathrm{NH}) \mathrm{ppm} .{ }^{13} \mathrm{C}$ NMR (62.89 MHz, d6-DMSO, $\left.25^{\circ} \mathrm{C}, \mathrm{TMS}\right) ; \delta=11.51\left(\mathrm{~s}, 2 \mathrm{C}, \mathrm{NHC}_{2} \mathrm{H}_{5}\right), 34.82\left(\mathrm{~s}, 2 \mathrm{C}, \mathrm{NHC}_{2} \mathrm{H}_{5}\right), 121.24(\mathrm{~d}$, ${ }^{3} J_{\mathrm{PC}}=4.7 \mathrm{~Hz}, 4 \mathrm{C}$, ortho-phenyl), 124.47 (s, 2 C, para-phenyl), 129.75 (s, 4 C, meta-phenyl), 151.01 (d, 2 C, ipso-phenyl) ppm. ${ }^{31} \mathrm{P}\left\{{ }^{1} \mathrm{H}\right\}$ and ${ }^{31} \mathrm{P}$ NMR $\left(101.25 \mathrm{MHz}, \mathrm{d} 6-\mathrm{DMSO}, 25^{\circ} \mathrm{C}\right.$, $\mathrm{H}_{3} \mathrm{PO}_{4}$ external $) ; \delta=-7.36\left(\mathrm{~d},{ }^{2} J_{\mathrm{PP}}=11.7 \mathrm{~Hz}\right),-8.55\left(\mathrm{~d},{ }^{2} J_{\mathrm{PP}}=11.9 \mathrm{~Hz}\right) \mathrm{ppm} . \mathrm{IR}(\mathrm{KBr}): \tilde{v}=$ $3153.1(\mathrm{~N}-\mathrm{H}), 2980.5(\mathrm{~s}), 1593.3(\mathrm{~s}), 1488.9$ (s), 1359.9 (s), $1252.0(\mathrm{P}=\mathrm{O}), 1202.4(\mathrm{P}=\mathrm{O})$, $1013.9(\mathrm{P}-\mathrm{O}), 931.5(\mathrm{P}-\mathrm{N}), 767.9(\mathrm{P}-\mathrm{N})$.

\section{$\left(\mathrm{C}_{6} \mathrm{H}_{5} \mathrm{O}\right)_{2} \mathrm{P}(\mathrm{O}) \mathrm{NHP}(\mathrm{O})\left(\mathrm{NHC}_{3} \mathrm{H}_{7}\right)_{2}(4)$}

powder sample; m.p. $154-156{ }^{\circ} \mathrm{C} .{ }^{1} \mathrm{H}$ NMR $\left(250.13 \mathrm{MHz}\right.$, d6-DMSO, $25^{\circ} \mathrm{C}$, TMS); ${ }^{13} \mathrm{C}$ NMR (62.89 MHz, d6-DMSO, $\left.25^{\circ} \mathrm{C}, \mathrm{TMS}\right) ; \delta=11.50$ (s, $\left.2 \mathrm{C}, \mathrm{NHC}_{3} \mathrm{H}_{7}\right), 21.19$ (s, $2 \mathrm{C}$, $\left.\mathrm{NHC}_{3} \mathrm{H}_{7}\right), 39.00\left(\mathrm{~s}, 2 \mathrm{C}, \mathrm{NHC}_{3} \mathrm{H}_{7}\right), 121.21\left(\mathrm{~d},{ }^{3} \mathrm{~J}_{\mathrm{PC}}=4.7 \mathrm{~Hz}, 4 \mathrm{C}\right.$, ortho-phenyl), 124.56 (s, $2 \mathrm{C}$, para-phenyl), 129.79 (s, $4 \mathrm{C}$, meta-phenyl), 151.81 (d, $2 \mathrm{C},{ }^{2} J_{\mathrm{PC}}=6.9 \mathrm{~Hz}$, ipso-phenyl) ppm. ${ }^{31} \mathrm{P}\left\{{ }^{1} \mathrm{H}\right\}$ and ${ }^{31} \mathrm{P}$ NMR $\left(101.25 \mathrm{MHz}, \mathrm{d} 6-\mathrm{DMSO}, 25^{\circ} \mathrm{C}, \mathrm{H}_{3} \mathrm{PO}_{4}\right.$ external $) ; \delta=-7.30(\mathrm{~m}),-7.82(\mathrm{~m})$ 
ppm. IR (KBr): $\tilde{v}=3063.9(\mathrm{~N}-\mathrm{H}), 2968.5(\mathrm{~s}), 1595.0(\mathrm{~s}), 1490.8(\mathrm{~s}), 1349.4(\mathrm{~s}), 1215.6(\mathrm{P}=\mathrm{O})$, $1205.6(\mathrm{P}=\mathrm{O}), 1010.4(\mathrm{P}-\mathrm{O}), 937.6(\mathrm{P}-\mathrm{N}), 763.1(\mathrm{P}-\mathrm{N})$.

\section{$\left(\mathrm{C}_{6} \mathrm{H}_{5} \mathrm{O}\right)_{2} \mathrm{P}(\mathrm{O}) \mathrm{NHP}(\mathrm{O})\left[\mathrm{N}\left(\mathrm{CH}_{3}\right)_{2}\right]_{2}(5)$}

powder sample; m.p. $166-168{ }^{\circ} \mathrm{C} .{ }^{1} \mathrm{H}$ NMR $\left(250.13 \mathrm{MHz}\right.$, d6-DMSO, $\left.25^{\circ} \mathrm{C}, \mathrm{TMS}\right) ; \delta=2.40$ $\left(\mathrm{m}, 12 \mathrm{H}, \mathrm{N}\left(\mathrm{CH}_{3}\right)_{2}\right), 7.17$ (t, $2 \mathrm{H}$, phenyl), 7.32 (t, $8 \mathrm{H}$, phenyl), $8.35(\mathrm{~b}, 1 \mathrm{H}, \mathrm{NH}) \mathrm{ppm} .{ }^{13} \mathrm{C}$ NMR (62.89 MHz, d6-DMSO, $\left.25^{\circ} \mathrm{C}, \mathrm{TMS}\right) ; \delta=27.02\left(\mathrm{~s}, 4 \mathrm{C}, \mathrm{N}\left(\mathrm{CH}_{3}\right)_{2}\right), 121.12\left(\mathrm{~d},{ }^{3} J_{\mathrm{PC}}=4.6\right.$ Hz, 4 C, ortho-phenyl), 124.67 (s, 2 C, para-phenyl), 129.36 (s, 4 C, meta-phenyl), 151.65 (d, 2 C, ipso-phenyl) ppm. ${ }^{31} \mathrm{P}\left\{{ }^{1} \mathrm{H}\right\}$ and ${ }^{31} \mathrm{P}$ NMR $\left(101.25 \mathrm{MHz}\right.$, d6-DMSO, $25^{\circ} \mathrm{C}, \mathrm{H}_{3} \mathrm{PO}_{4}$ external); $\delta=-7.23\left(\mathrm{~d},{ }^{2} J_{\mathrm{PP}}=9.9 \mathrm{~Hz}\right),-8.14\left(\mathrm{~d},{ }^{2} J_{\mathrm{PP}}=9.7 \mathrm{~Hz}\right) \mathrm{ppm} . \mathrm{IR}(\mathrm{KBr}): \tilde{v}=3112.6(\mathrm{~N}-\mathrm{H}), 2757.1$ (s), $1592.9(\mathrm{~s}), 1491.0(\mathrm{~s}), 1342.2(\mathrm{~s}), 1244.6(\mathrm{P}=\mathrm{O}), 1192.4(\mathrm{P}=\mathrm{O}), 1052.3(\mathrm{P}-\mathrm{O}), 932.6(\mathrm{P}-\mathrm{N})$, $771.3(\mathrm{P}-\mathrm{N})$.

\section{$\left(\mathrm{C}_{6} \mathrm{H}_{5} \mathrm{O}\right)_{2} \mathrm{P}(\mathrm{O}) \mathrm{NHP}(\mathrm{O})\left[\mathrm{N}\left(\mathrm{C}_{2} \mathrm{H}_{5}\right)_{2}\right]_{2}(6)$}

powder sample; m.p. $164-167{ }^{\circ} \mathrm{C} .{ }^{1} \mathrm{H}$ NMR $\left(250.13 \mathrm{MHz}, \mathrm{d} 6-\mathrm{DMSO}, 25^{\circ} \mathrm{C}, \mathrm{TMS}\right) ; \delta=1.18$ (m, $\left.12 \mathrm{H}, \mathrm{N}\left(\mathrm{C}_{2} \mathrm{H}_{5}\right)_{2}\right), 2.80\left(\mathrm{~m}, 8 \mathrm{H}, \mathrm{N}\left(\mathrm{C}_{2} \mathrm{H}_{5}\right)_{2}\right), 7.17$ (t, $2 \mathrm{H}$, phenyl), 7.29-7.33 (t, $8 \mathrm{H}$, phenyl), $8.25(\mathrm{~b}, 1 \mathrm{H}, \mathrm{NH}) \mathrm{ppm} .{ }^{13} \mathrm{C}$ NMR $\left(62.89 \mathrm{MHz}, \mathrm{d} 6-\mathrm{DMSO}, 25^{\circ} \mathrm{C}, \mathrm{TMS}\right) ; \delta=11.46$ (s, $4 \mathrm{C}$, $\left.\mathrm{N}\left(\mathrm{C}_{2} \mathrm{H}_{5}\right)_{2}\right), 41.62$ (s, $\left.4 \mathrm{C}, \mathrm{N}\left(\mathrm{C}_{2} \mathrm{H}_{5}\right)_{2}\right), 121.17$ (d, $4 \mathrm{C}$, ortho-phenyl), 124.65 (s, 2 C, paraphenyl), 129.81 (s, 4 C, meta-phenyl), 150.65 (d, $2 \mathrm{C}$, ipso-phenyl) ppm. ${ }^{31} \mathrm{P}\left\{{ }^{1} \mathrm{H}\right\}$ and ${ }^{31} \mathrm{P}$ NMR $\left(101.25 \mathrm{MHz}, \mathrm{d} 6-\mathrm{DMSO}, 25^{\circ} \mathrm{C}, \mathrm{H}_{3} \mathrm{PO}_{4}\right.$ external); $\delta=-7.38\left(\mathrm{~d},{ }^{2} J_{\mathrm{PP}}=8.9 \mathrm{~Hz}\right),-8.63\left(\mathrm{~d},{ }^{2} J_{\mathrm{PP}}=8.2\right.$ Hz) ppm. IR (KBr): $\tilde{v}=3066.1(\mathrm{~N}-\mathrm{H}), 2706.6(\mathrm{~s}), 1595.5(\mathrm{~s}), 1492.2(\mathrm{~s}), 1356.9(\mathrm{~s}), 1247.6$ $(\mathrm{P}=\mathrm{O}), 1200.9(\mathrm{P}=\mathrm{O}), 1005.0(\mathrm{P}-\mathrm{O}), 936.5(\mathrm{P}-\mathrm{N}), 763.5(\mathrm{P}-\mathrm{N})$.

\section{$\left(\mathrm{C}_{6} \mathrm{H}_{5} \mathrm{O}\right)_{2} \mathrm{P}(\mathrm{O}) \mathrm{NHP}(\mathrm{O})\left[\mathrm{N}\left(\mathrm{C}_{4} \mathrm{H}_{9}\right)_{2}\right]_{2}(7)$}


oil sample; ${ }^{1} \mathrm{H}$ NMR $\left(250.13 \mathrm{MHz}, \mathrm{d} 6-\mathrm{DMSO}, 25^{\circ} \mathrm{C}, \mathrm{TMS}\right) ; \delta=0.85\left(\mathrm{~m}, 12 \mathrm{H}, \mathrm{N}\left(\mathrm{C}_{4} \mathrm{H}_{9}\right)_{2}\right)$, $1.27\left(\mathrm{~m}, 8 \mathrm{H}, \mathrm{N}\left(\mathrm{C}_{4} \mathrm{H}_{9}\right)_{2}\right), 1.57\left(\mathrm{~m}, 8 \mathrm{H}, \mathrm{N}\left(\mathrm{C}_{4} \mathrm{H}_{9}\right)_{2}\right), 2.74\left(\mathrm{~m}, 8 \mathrm{H}, \mathrm{N}\left(\mathrm{C}_{4} \mathrm{H}_{9}\right)_{2}\right), 7.17$ (t, $2 \mathrm{H}$, phenyl), 7.31-7.33 (t, $8 \mathrm{H}$, phenyl), 8.29 (b, $1 \mathrm{H}, \mathrm{NH})$ ppm. ${ }^{13} \mathrm{C}$ NMR (62.89 MHz, d6-DMSO, $25^{\circ} \mathrm{C}$, TMS); $\delta=14.07\left(\mathrm{~s}, 4 \mathrm{C}, \mathrm{N}\left(\mathrm{C}_{4} \mathrm{H}_{9}\right)_{2}\right), 20.04\left(\mathrm{~s}, 4 \mathrm{C}, \mathrm{N}\left(\mathrm{C}_{4} \mathrm{H}_{9}\right)_{2}\right), 28.64\left(\mathrm{~s}, 4 \mathrm{C}, \mathrm{N}\left(\mathrm{C}_{4} \mathrm{H}_{9}\right)_{2}\right), 47.25(\mathrm{~s}$, $\left.4 \mathrm{C}, \mathrm{N}\left(\mathrm{C}_{4} \mathrm{H}_{9}\right)_{2}\right), 121.17$ (d, ${ }^{3} \mathrm{JC}_{\mathrm{PC}}=4.7 \mathrm{~Hz}, 4 \mathrm{C}$, ortho-phenyl), 124.63 (s, $2 \mathrm{C}$, para-phenyl), 129.78 (s, 4 C, meta-phenyl), 151.65 (d, 2 C, ipso-phenyl) ppm. ${ }^{31} \mathrm{P}\left\{{ }^{1} \mathrm{H}\right\}$ and ${ }^{31} \mathrm{P}$ NMR (101.25 $\mathrm{MHz}, \mathrm{d6}-\mathrm{DMSO}, 25^{\circ} \mathrm{C}, \mathrm{H}_{3} \mathrm{PO}_{4}$ external $) ; \delta=-7.34\left(\mathrm{~d},{ }^{2} J_{\mathrm{PP}}=9.1 \mathrm{~Hz}\right),-8.50\left(\mathrm{~d},{ }^{2} J_{\mathrm{PP}}=9.3 \mathrm{~Hz}\right)$ ppm. IR (KBr): $\tilde{v}=3412.7(\mathrm{~N}-\mathrm{H}), 2961.8(\mathrm{~s}), 2871.5(\mathrm{~s}), 1594.8(\mathrm{~s}), 1491.1(\mathrm{~s}), 1386.8(\mathrm{~s})$, $1258.3(\mathrm{P}=\mathrm{O}), 1198.7(\mathrm{P}=\mathrm{O}), 1011.3(\mathrm{P}-\mathrm{O}), 929.2(\mathrm{P}-\mathrm{N}), 769.6(\mathrm{P}-\mathrm{N})$.

\section{$\left(\mathrm{C}_{6} \mathrm{H}_{5} \mathrm{O}\right)_{2} \mathrm{P}(\mathrm{O}) \mathrm{NHP}(\mathrm{O})\left(\mathrm{NC}_{4} \mathrm{H}_{8} \mathrm{O}\right)_{2}(8)$}

oil sample; ${ }^{1} \mathrm{H}$ NMR $\left(500.13 \mathrm{MHz}, \mathrm{d} 6-\mathrm{DMSO}, 25^{\circ} \mathrm{C}, \mathrm{TMS}\right) ; \delta=2.91\left(\mathrm{~m}, 8 \mathrm{H}, \mathrm{NC}_{4} \mathrm{H}_{8} \mathrm{O}\right), 3.69$ (m, $8 \mathrm{H}, \mathrm{NC}_{4} \mathrm{H}_{8} \mathrm{O}$ ), 7.12 (t, $2 \mathrm{H}$, phenyl), 7.27 (d, $4 \mathrm{H}$, phenyl), 7.31 (t, $4 \mathrm{H}$, phenyl), 8.10 (b, 1 H, NH) ppm. ${ }^{13} \mathrm{C}$ NMR (125.75 MHz, d6-DMSO, $\left.25^{\circ} \mathrm{C}, \mathrm{TMS}\right) ; \delta=42.71\left(\mathrm{~s}, 4 \mathrm{C}, \mathrm{NC}_{4} \mathrm{H}_{8} \mathrm{O}\right)$, $63.43\left(\mathrm{~s}, 4 \mathrm{C}, \mathrm{NC}_{4} \mathrm{H}_{8} \mathrm{O}\right), 120.59\left(\mathrm{~d},{ }^{3} \mathrm{~J}_{\mathrm{PC}}=4.7 \mathrm{~Hz}, 4 \mathrm{C}\right.$, ortho-phenyl), 124.14 (s, $2 \mathrm{C}$, paraphenyl), 129.30 (s, $4 \mathrm{C}$, meta-phenyl), $151.14\left(\mathrm{~d},{ }^{2} J_{\mathrm{PC}}=6.5 \mathrm{~Hz}, 2 \mathrm{C}\right.$, ipso-phenyl) ppm. ${ }^{31} \mathrm{P}\left\{{ }^{1} \mathrm{H}\right\}$ and ${ }^{31} \mathrm{P}$ NMR $\left(202.45 \mathrm{MHz}, \mathrm{d} 6-\mathrm{DMSO}, 25^{\circ} \mathrm{C}, \mathrm{H}_{3} \mathrm{PO}_{4}\right.$ external); $\delta=-4.81(\mathrm{~m}),-5.43(\mathrm{~m})$ ppm. IR (KBr): $\tilde{v}=3036.9(\mathrm{~N}-\mathrm{H}), 2724.3(\mathrm{~s}), 1598.2(\mathrm{~s}), 1486.8(\mathrm{~s}), 1382.6(\mathrm{~s}), 1250.3(\mathrm{P}=\mathrm{O})$, $1165.4(\mathrm{P}=\mathrm{O}), 1074.2(\mathrm{P}-\mathrm{O}), 919.1(\mathrm{P}-\mathrm{N}), 774.0(\mathrm{P}-\mathrm{N})$.

\section{$\left(\mathrm{C}_{6} \mathrm{H}_{5} \mathrm{O}\right)_{2} \mathrm{P}(\mathrm{O}) \mathrm{NHP}(\mathrm{O})\left(\mathrm{NH}-\left(\mathrm{NC}_{4} \mathrm{H}_{8} \mathrm{O}\right)_{2}(9)\right.$}

powder sample; m.p. $183-186{ }^{\circ} \mathrm{C} .{ }^{1} \mathrm{H}$ NMR $\left(500.13 \mathrm{MHz}, \mathrm{d} 6-\mathrm{DMSO}, 25^{\circ} \mathrm{C}, \mathrm{TMS}\right) ; \delta=2.44$ $\left(\mathrm{m}, 8 \mathrm{H}, \mathrm{NC}_{4} \mathrm{H}_{8} \mathrm{O}\right), 3.34\left(\mathrm{~m}, 8 \mathrm{H}, \mathrm{NC}_{4} \mathrm{H}_{8} \mathrm{O}\right), 5.46\left(\mathrm{~d},{ }^{2} J_{\mathrm{PNH}}=7.2 \mathrm{~Hz}, 2 \mathrm{H}, \mathrm{NH}\right), 7.08(\mathrm{t}, 2 \mathrm{H}$, phenyl), 7.21-7.31 (m, $4 \mathrm{H}$, phenyl), 7.36-7.39 (m, $4 \mathrm{H}$, phenyl), 8.47 (b, $1 \mathrm{H}, \mathrm{NH}) \mathrm{ppm} .{ }^{13} \mathrm{C}$ 
NMR (125.76 MHz, d6-DMSO, 25 $\left.{ }^{\circ} \mathrm{C}, \mathrm{TMS}\right) ; \delta=55.33\left(\mathrm{~s}, 4 \mathrm{C}, \mathrm{NC}_{4} \mathrm{H}_{8} \mathrm{O}\right), 65.59(\mathrm{~s}, 4 \mathrm{C}$, $\mathrm{NC}_{4} \mathrm{H}_{8} \mathrm{O}$ ), 121.78 (d, 4 C, ortho-phenyl), 124.14 (s, 2 C, para-phenyl), 130.52 (s, 4 C, metaphenyl), 151.48 (d, 2 C, ipso-phenyl) ppm. ${ }^{31} \mathrm{P}\left\{{ }^{1} \mathrm{H}\right\}$ and ${ }^{31} \mathrm{P}$ NMR (202.45 MHz, d6-DMSO, $25^{\circ} \mathrm{C}, \mathrm{H}_{3} \mathrm{PO}_{4}$ external); $\delta=-5.23--5.36(\mathrm{~m}) \mathrm{ppm} . \mathrm{IR}(\mathrm{KBr}): \tilde{v}=3112.6(\mathrm{~N}-\mathrm{H}), 2967.9(\mathrm{~s})$, $2861.9(\mathrm{~s}), 1591.4(\mathrm{~s}), 1492.3(\mathrm{~s}), 1369.4(\mathrm{~s}), 1241.2(\mathrm{P}=\mathrm{O}), 1200.6(\mathrm{P}=\mathrm{O}), 1001.0(\mathrm{P}-\mathrm{O}), 936.2$ $(\mathrm{P}-\mathrm{N}), 758.4(\mathrm{P}-\mathrm{N})$.

\section{$\left(\mathrm{C}_{6} \mathrm{H}_{5} \mathrm{O}\right)_{2} \mathrm{P}(\mathrm{O}) \mathrm{NHP}(\mathrm{O})\left(\mathrm{NH}-\left(\mathrm{NC}_{5} \mathrm{H}_{10}\right)_{2}(10)\right.$}

powder sample; m.p. $170-172{ }^{\circ} \mathrm{C} .{ }^{1} \mathrm{H}$ NMR $\left(500.13 \mathrm{MHz}\right.$, d6-DMSO, $\left.25^{\circ} \mathrm{C}, \mathrm{TMS}\right) ; \delta=1.34$ (m, $\left.4 \mathrm{H}, \mathrm{NC}_{5} \mathrm{H}_{10}\right), 1.57\left(\mathrm{~m}, 8 \mathrm{H}, \mathrm{NC}_{5} \mathrm{H}_{10}\right), 2.86\left(\mathrm{~m}, 8 \mathrm{H}, \mathrm{NC}_{5} \mathrm{H}_{10}\right), 7.11$ (t, $2 \mathrm{H}$, phenyl), 7.26 (d, $4 \mathrm{H}$, phenyl), 7.31 (t, $4 \mathrm{H}$, phenyl), 8.00 (b, $1 \mathrm{H}, \mathrm{NH}) \mathrm{ppm} .{ }^{13} \mathrm{C}$ NMR (125.75 MHz, d6-DMSO, $\left.25^{\circ} \mathrm{C}, \mathrm{TMS}\right) ; \delta=23.86\left(\mathrm{~s}, 2 \mathrm{C}, \mathrm{NC}_{5} \mathrm{H}_{10}\right), 55.38$ (s, $4 \mathrm{C}, \mathrm{NC}_{5} \mathrm{H}_{10}$ ), 57.61 (s, $4 \mathrm{C}, \mathrm{NC}_{5} \mathrm{H}_{10}$ ), 121.76 (d, 4 C, ortho-phenyl), 124.02 (s, 2 C, para-phenyl), 130.46 (s, 4 C, meta-phenyl), 151.58 (d, 2 C, ipso-phenyl) ppm. ${ }^{31} \mathrm{P}\left\{{ }^{1} \mathrm{H}\right\}$ and ${ }^{31} \mathrm{P}$ NMR (202.45 MHz, d6-DMSO, $25^{\circ} \mathrm{C}, \mathrm{H}_{3} \mathrm{PO}_{4}$ external); $\delta=-5.21(\mathrm{~m}) \mathrm{ppm} . \mathrm{IR}(\mathrm{KBr}): \tilde{v}=3371.6(\mathrm{~N}-\mathrm{H}), 3207.3(\mathrm{~s}), 2865.5(\mathrm{~s}), 1595.6(\mathrm{~s}), 1490.3(\mathrm{~s})$, $1315.6(\mathrm{~s}), 1244.1(\mathrm{P}=\mathrm{O}), 1198.3(\mathrm{P}=\mathrm{O}), 1064.3(\mathrm{P}-\mathrm{O}), 932.3(\mathrm{P}-\mathrm{N}), 764.8(\mathrm{P}-\mathrm{N})$.

\section{$\left(\mathrm{C}_{6} \mathrm{H}_{5} \mathrm{O}\right)_{2} \mathrm{P}(\mathrm{O}) \mathrm{NHP}(\mathrm{O})\left(\mathrm{NH}\left(\mathrm{C}_{6} \mathrm{H}_{5}\right)_{2}(11)\right.$}

powder sample; m.p. $135-137^{\circ} \mathrm{C} .{ }^{1} \mathrm{H}$ NMR $\left(250.13 \mathrm{MHz}, \mathrm{d} 6-\mathrm{DMSO}, 25^{\circ} \mathrm{C}, \mathrm{TMS}\right) ; \delta=6.54-$ $6.65(\mathrm{~m}, 2 \mathrm{H}, \mathrm{N}-\mathrm{H}), 7.06$ (t, $2 \mathrm{H}$, phenyl), 7.22 (t, $2 \mathrm{H}$, phenyl), 7.27 (m, $8 \mathrm{H}$, phenyl), 8.30 (m, 4 $\mathrm{H}$, phenyl), 8,41 (m, $4 \mathrm{H}$, phenyl), 8.40 (b, $1 \mathrm{H}, \mathrm{NH}) \mathrm{ppm} .{ }^{13} \mathrm{C}$ NMR (62.89 MHz, d6-DMSO, $\left.25^{\circ} \mathrm{C}, \mathrm{TMS}\right) ; 114.05\left(\mathrm{~m}, 4 \mathrm{C}\right.$, ortho- $\left.-\mathrm{HNC}_{6} \mathrm{H}_{5}\right), 120.37\left(\mathrm{~d},{ }^{3} \mathrm{JC}_{\mathrm{PC}}=4.8 \mathrm{~Hz}, 4 \mathrm{C}\right.$, ortho- $\left.\mathrm{OC}_{6} \mathrm{H}_{5}\right)$, $124.67\left(\mathrm{~m}, 2 \mathrm{C}\right.$, para $\left.-\mathrm{OC}_{6} \mathrm{H}_{5}\right), 128.71\left(\mathrm{~m}, 2 \mathrm{C}\right.$, para $\left.-\mathrm{HNC}_{6} \mathrm{H}_{5}\right), 129.50\left(\mathrm{~m}, 4 \mathrm{C}\right.$, meta $\left.-\mathrm{OC}_{6} \mathrm{H}_{5}\right)$, 130. $05\left(\mathrm{~m}, 4 \mathrm{C}\right.$, meta $\left.-\mathrm{HNC}_{6} \mathrm{H}_{5}\right), 136.48$ (s, $2 \mathrm{C}$, ipso- $\left.-\mathrm{HNC}_{6} \mathrm{H}_{5}\right), 150.48\left(\mathrm{~d},{ }^{2} J_{\mathrm{PC}}=6.6 \mathrm{~Hz}, 2 \mathrm{C}\right.$, 
ipso- $\left.\mathrm{OC}_{6} \mathrm{H}_{5}\right)$ ppm. ${ }^{31} \mathrm{P}\left\{{ }^{1} \mathrm{H}\right\}$ and ${ }^{31} \mathrm{P}$ NMR (101.25 MHz, d6-DMSO, 25 ${ }^{\circ} \mathrm{C}, \mathrm{H}_{3} \mathrm{PO}_{4}$ external); $\delta=-$

$6.44\left(\mathrm{~d},{ }^{2} J_{\mathrm{PP}}=9.9 \mathrm{~Hz}\right),-9.53\left(\mathrm{~d},{ }^{2} J_{\mathrm{PP}}=9.9 \mathrm{~Hz}\right) \mathrm{ppm} . \mathrm{IR}(\mathrm{KBr}): \tilde{v}=3020.5(\mathrm{~N}-\mathrm{H}), 2926.4(\mathrm{~s})$, 1592.1 (s), 1491.8 (s), 1360.9 (s), $1250.8(\mathrm{P}=\mathrm{O}), 1202.0(\mathrm{P}=\mathrm{O}), 1047.6(\mathrm{P}-\mathrm{O}), 947.5(\mathrm{P}-\mathrm{N})$, $760.2(\mathrm{P}-\mathrm{N})$.

\subsection{AChE purification}

Synchronized third instar larvae were homogenized in phosphate buffer $(20 \mathrm{mM}$; pH 7.0$)$ containing $0.1 \%$ triton $\mathrm{X}-100$ using a hand-held glass homogenizer. The homogenate was centrifuged at $14,000 \times \mathrm{g}$ for $30 \mathrm{~min}$ at $4{ }^{\circ} \mathrm{C}$ twice. Supernatant was used for AChE purification.

The procainamide-based AChE affinity column was used for purification of AChE. The matrix was prepared based on the method of Pasteur et al. (1997) [20] using ECH Sepharose 4B. Procainamide (1.36 g procainamide in $10 \mathrm{ml}$ water) were mixed with EEDQ solutions $(0.124 \mathrm{~g}$ EEDQ in $10 \mathrm{ml}$ ethanol) and then $20 \mathrm{ml} \mathrm{ECH} \mathrm{Sepharose} \mathrm{4B} \mathrm{were} \mathrm{added.} \mathrm{The} \mathrm{coupling} \mathrm{reaction}$ was done by gently mixing the solution at $4{ }^{\circ} \mathrm{C}$ for $12 \mathrm{~h}$. The procainamide-coupled Sepharose 4B was packed to a $1 \times 8.5 \mathrm{~cm}$ glass column and washed successively with $50 \%$ ethanol, $20 \mathrm{mM}$ Tris- $\mathrm{HCl}$ buffer ( $\mathrm{pH} 7.0$ ), and $1 \mathrm{M} \mathrm{NaCl}$ solution. The column then was equilibrated with 0.05 M phosphate buffer ( $\mathrm{pH} 7.0)$ containing $0.1 \%(\mathrm{v} / \mathrm{v})$ triton X-100 and $0.05 \mathrm{M} \mathrm{NaCl}$ (PTS buffer) [21]. The supernatant loaded on a procainamide-based AChE affinity column and enzyme eluted with a flow rate of $0.5 \mathrm{ml} / \mathrm{min}$. AChE activities in fractions were measured based on the Ellman et al. method [15] as mentioned above.

\subsubsection{Determination of $p H$ optimum and effect of temperature on AChE activity}

The $\mathrm{pH}$ profiles of the AChE were characterized in a universal buffer comprising phosphate, borate and acetate (40 mM of each) adjusted to various $\mathrm{pHs}(\mathrm{pH} 3$ to 12) by adding $\mathrm{HCl}$ or $\mathrm{NaOH}$ for acidic and basic $\mathrm{pH}$ values, respectively. Before determining AChE activity, the en- 
zyme and buffer mixtures were incubated at different $\mathrm{pHs}$ for $4 \mathrm{~min}$. Then the enzyme activity was measured as kinetic mode based on the Ellman et al. method [15]. Also, the activity of AChE was measured by incubating the reaction mixtures in optimal $\mathrm{pH}$ value $(20 \mathrm{mM}$ phosphate buffer) at different temperatures ranging from 15 to $65^{\circ} \mathrm{C}$ with $10^{\circ} \mathrm{C}$ intervals.

\subsubsection{Inhibition assay of insect AChE}

Inhibition assays were conducted by the pre-incubating the purified AChE with different concentrations of PHA derivatives for 10 minutes. Afterward, the substrate was added to the reaction mixture containing phosphate buffer, $\mathrm{pH} 7.0$ and DTNB. Residual activity was measured kinetically at $412 \mathrm{~nm}$ as mentioned above. Median inhibition concentration $\left(\mathrm{IC}_{50}\right)$ and $\mathrm{IC}_{25}$ were calculated by probit analysis using the POLOPC software [14].

\subsubsection{Mechanism of enzyme inhibition by compounds}

To investigate the mechanism of inhibition, the effect of $\mathrm{IC}_{50}$ and $\mathrm{IC}_{25}$ concentrations of each inhibitor were investigated on AChE activity in presence of different concentrations of the substrate $(10,5,2.5,1.25$ and $0.625 \mathrm{mM})$. The $\mathrm{K}_{\mathrm{m}}$ and $\mathrm{V}_{\max }$ values in presence and absence of inhibitors were estimated from Lineweaver-Burk plots. Also, the inhibitory constant $\mathrm{K}_{\mathrm{i}}$ is calculated [22].

\subsection{Statistical analysis}

The $\mathrm{LC}_{50}$ values and $95 \%$ confidence intervals were calculated from probit regressions using the POLO-PC computer program [14]. One-way analysis of variance (ANOVA) was employed for data analysis [23]. Differences between treatments were evaluated using Tukey's test and were considered significant when the probability level $\mathrm{p} \leq 0.05$.

QSAR studies were conducted for identifying the effect of physicochemical parameters on the AChE inhibition activity [24]. The stepwise multiple linear regression procedure is a popular me- 
thod in QSAR studies for selection descriptors. The MLR method was performed by the software package SPSS 16.0 for selection of the descriptors [25]. The electronic and structural descriptors are obtained by either the quantum chemical calculations, theoretical and experimental studies. The electronic descriptors comprised the energy of frontier orbital ( $E_{\mathrm{HOMO}}$ and $\left.E_{\mathrm{LUMO}}\right)$, electrophilicity $(\omega)$, polarizability $(P L)$, the charge difference between the atoms in functional groups and the net atomic charges $(Q)$. Similarly, the structural descriptors are hydrophobic coefficient $(\log P)$, dipole moment $(\mu)$ and molecular volume $(M v)$. The toxicities of phosphorhydrazide analogues are expressed in terms of $\log \left(1 / I_{50}\right)$ as an anti-cholinesterase activity. The descriptor values were related with toxicity using MLR analysis. MLR of descriptors selected for biological activity, leads to the problem of multicollinearity. This problem can be solved by using the principal component analysis (PCA). These linear combinations form a new set of variables, called principal components (PCs), which are mutually orthogonal. The first PC contains the largest variance and the second new variable contains the second largest variance, and so on. The variable selection in this PCA study was done by using the Fisher's weights. The descriptors with higher correlation coefficient and lower correlation $(|r|<0.5)$ to $\log \left(1 / I_{50}\right)$ were selected to carry out stepwise MLR analysis and to optimize the QSAR equation [26]. All quantum chemical calculations were carried out by using the Gaussian 03 program package [27].

\section{Results}

\subsection{Spectroscopic study}

The ${ }^{31} \mathrm{P}$ NMR chemical shift at room temperature in DMSO appears as two separated peaks. For example, $\delta^{31} \mathrm{P}$ and ${ }^{2} J_{\mathrm{PP}}$ values of compounds $\left(\mathrm{C}_{6} \mathrm{H}_{5} \mathrm{O}\right)_{2} \mathrm{P}(\mathrm{O})-\mathrm{NH}-\mathrm{P}(\mathrm{O})\left(\mathrm{NHC}_{2} \mathrm{H}_{5}\right)_{2}(3)$ and $\left(\mathrm{C}_{6} \mathrm{H}_{5} \mathrm{O}\right)_{2} \mathrm{P}(\mathrm{O})-\mathrm{NH}-\mathrm{P}(\mathrm{O})\left(\mathrm{NHC}_{6} \mathrm{H}_{5}\right)_{2}(\mathbf{1 1})$ reveals in the rang $-7.36 \mathrm{ppm}$ and ${ }^{2} J_{\mathrm{PP}}=11.7 \mathrm{~Hz}$ on 
other $-8.55 \mathrm{ppm}$ and ${ }^{2} J_{\mathrm{PP}}=11.9 \mathrm{~Hz}$ for 3 as well as in the rang $-6.44 \mathrm{ppm}$ and ${ }^{2} J_{\mathrm{PP}}=9.9 \mathrm{~Hz}$ on other $-9.53 \mathrm{ppm}$ and ${ }^{2} J_{\mathrm{PP}}=9.9 \mathrm{~Hz}$ for 11 (Fig. 1).

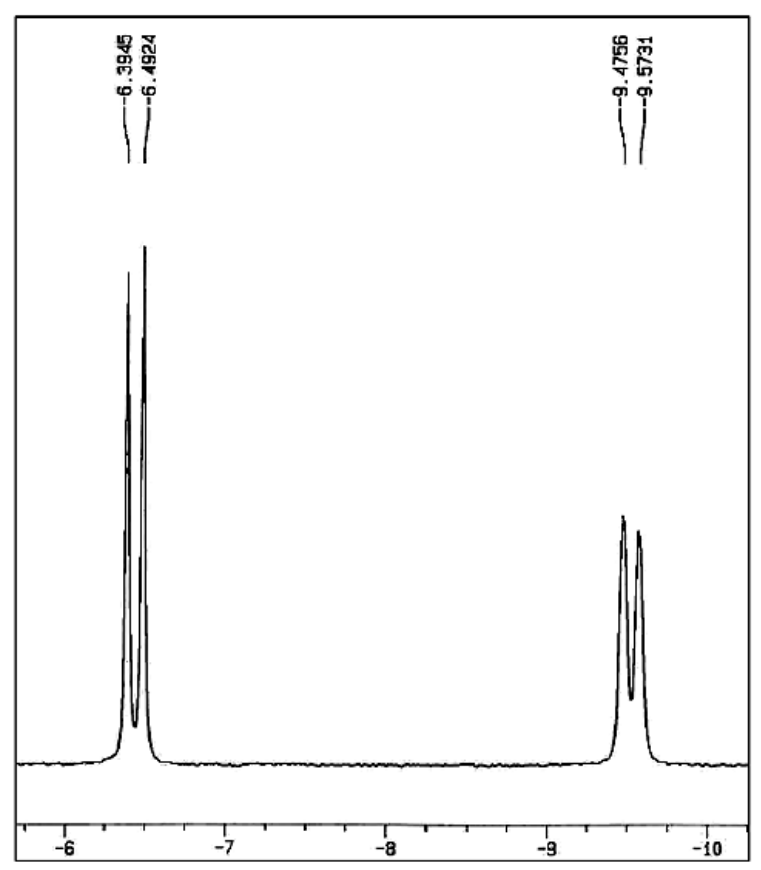

Fig. 1. The ${ }^{31} \mathrm{P}$ NMR chemical shift at room temperature in DMSO

Acidic proton of $\mathrm{N}-\mathrm{H}$ group of $\mathrm{P}(\mathrm{O})-\mathrm{NH}-\mathrm{P}(\mathrm{O})$ moiety in ${ }^{1} \mathrm{H}$ NMR spectra of compounds 9 and $\mathbf{1 0}$ exhibited as a broad peak due to resonance between two phosphoryl groups in the range $8.00 \mathrm{ppm}$ to $8.47 \mathrm{ppm}$, respectively. The analysis of the IR spectra indicated that the fundamental $v(\mathrm{P}=\mathrm{O})$ stretching modes for compounds 1-11 appeared at the range $1202-1250 \mathrm{~cm}^{-1}$. Moreover, the $\mathrm{N}-\mathrm{H}$ stretching frequencies for all compounds were observed at the range of $2940-3483 \mathrm{~cm}^{-1}$.

\subsection{Screening compounds on third instar larvae of X. luteola}

In this research, the toxicities of 36 temephos derivative (Scheme 2) were bioassayed on $X$. luteola larvae in order to find novel insecticide. Screening test with concentration of $5000 \mathrm{mg} / \mathrm{l} \mathrm{in-}$ dicated that twelve compounds exhibited mortality more than fifty percent. The result of the second screening test revealed that when the concentration of $2500 \mathrm{mg} / \mathrm{l}$ was used, four compounds had more than $75 \%$ mortality (Table 1 ). 


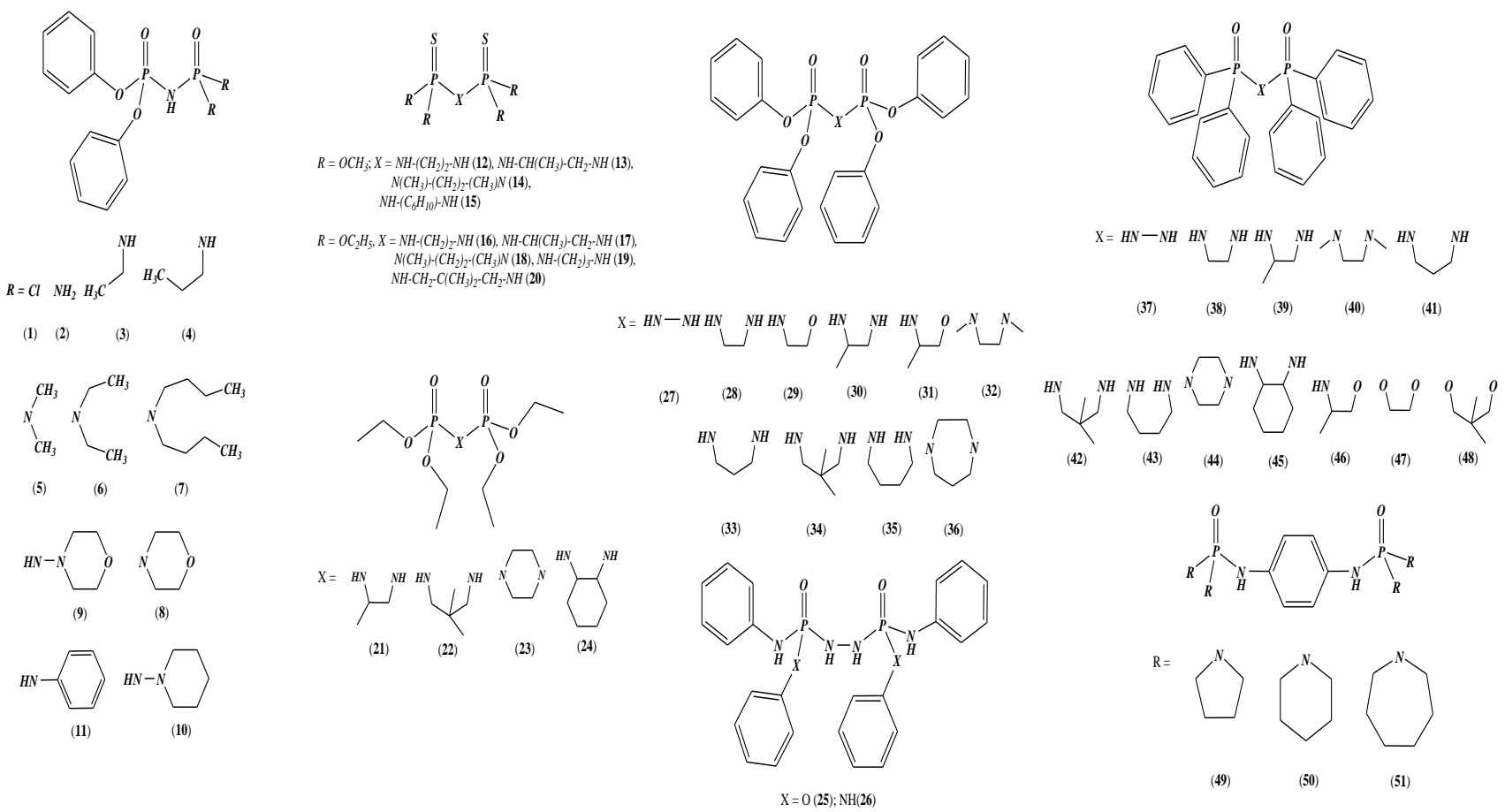

Scheme 2. temephos derivative

Table 1. Toxicity of temephos derivative compounds on last instar larvae of X. luteola (in vivo test) and their half maximal inhibitory concentration $\left(\mathrm{IC}_{50}\right)$ on $\mathrm{AChE}$ activity

\begin{tabular}{|c|c|c|c|c|c|}
\hline No. & Formula & $\begin{array}{c}\text { Mortality\% } \\
5000 \mathrm{mg} / \mathrm{l}\end{array}$ & $\begin{array}{c}\text { Mortality \% } \\
2500 \text { mg/l }\end{array}$ & $\begin{array}{c}I_{50} \\
\mathrm{mg} / \mathbf{l}\end{array}$ & Ref. \\
\hline 6 & $\left(\mathrm{C}_{6} \mathrm{H}_{5} \mathrm{O}\right)_{2} \mathrm{P}(\mathrm{O}) \mathrm{NHP}(\mathrm{O})\left[\mathrm{N}\left(\mathrm{C}_{2} \mathrm{H}_{5}\right)_{2}\right]_{2}$ & 10 & - & 116.13 & a \\
\hline 9 & $\left(\mathrm{C}_{6} \mathrm{H}_{5} \mathrm{O}\right)_{2} \mathrm{P}(\mathrm{O}) \mathrm{NHP}(\mathrm{O})\left(\mathrm{NH}-\left(\mathrm{NC}_{4} \mathrm{H}_{8} \mathrm{O}\right)_{2}\right.$ & 60 & 20 & 91.10 & $\mathrm{a}$ \\
\hline 10 & $\left(\mathrm{C}_{6} \mathrm{H}_{5} \mathrm{O}\right)_{2} \mathrm{P}(\mathrm{O}) \mathrm{NHP}(\mathrm{O})\left(\mathrm{NH}-\left(\mathrm{NC}_{5} \mathrm{H}_{10}\right)_{2}\right.$ & - & - & 77.33 & $\mathrm{a}$ \\
\hline 12 & $\left(\mathrm{CH}_{3} \mathrm{O}\right)_{2} \mathrm{P}(\mathrm{S}) \mathrm{NH}-\left(\mathrm{CH}_{2}\right)_{2}-\mathrm{HNP}(\mathrm{S})\left(\mathrm{OCH}_{3}\right)_{2}$ & - & - & 185.79 & [18] \\
\hline 13 & $\left(\mathrm{CH}_{3} \mathrm{O}\right)_{2} \mathrm{P}(\mathrm{S}) \mathrm{NH}-\mathrm{CH}\left(\mathrm{CH}_{3}\right)-\mathrm{CH}_{2}-\mathrm{HNP}(\mathrm{S})\left(\mathrm{OCH}_{3}\right)_{2}$ & 10 & - & 189.63 & [18] \\
\hline 14 & $\left(\mathrm{CH}_{3} \mathrm{O}\right)_{2} \mathrm{P}(\mathrm{S}) \mathrm{N}\left(\mathrm{CH}_{3}\right)-\mathrm{CH}_{2}-\mathrm{CH}_{2}-\left(\mathrm{CH}_{3}\right) \mathrm{NP}(\mathrm{S})\left(\mathrm{OCH}_{3}\right)_{2}$ & 15 & - & 71.37 & [18] \\
\hline 15 & $\left(\mathrm{CH}_{3} \mathrm{O}\right)_{2} \mathrm{P}(\mathrm{S}) \mathrm{NH}\left(\mathrm{C}_{6} \mathrm{H}_{10}\right) \mathrm{HNP}(\mathrm{S})\left(\mathrm{OCH}_{3}\right)_{2}$ & - & - & 99.15 & [18] \\
\hline 16 & $\left(\mathrm{CH}_{3} \mathrm{CH}_{2} \mathrm{O}\right)_{2} \mathrm{P}(\mathrm{S}) \mathrm{NH}-\left(\mathrm{CH}_{2}\right)_{2}-\mathrm{HNP}(\mathrm{S})\left(\mathrm{OCH}_{2} \mathrm{CH}_{3}\right)_{2}$ & 20 & - & 40.06 & [18] \\
\hline 17 & $\left(\mathrm{CH}_{3} \mathrm{CH}_{2} \mathrm{O}\right)_{2} \mathrm{P}(\mathrm{S}) \mathrm{NH}-\mathrm{CH}\left(\mathrm{CH}_{3}\right)-\mathrm{CH}_{2}-\mathrm{HNP}(\mathrm{S})\left(\mathrm{OCH}_{2} \mathrm{CH}_{3}\right)_{2}$ & - & - & 150.74 & [18] \\
\hline 18 & $\left(\mathrm{CH}_{3} \mathrm{CH}_{2} \mathrm{O}\right)_{2} \mathrm{P}(\mathrm{S}) \mathrm{NH}-\left(\mathrm{CH}_{2}\right)_{2}-\mathrm{HNP}(\mathrm{S})\left(\mathrm{OCH}_{2} \mathrm{CH}_{3}\right)_{2}$ & 20 & - & 50.56 & [18] \\
\hline 19 & $\left(\mathrm{CH}_{3} \mathrm{CH}_{2} \mathrm{O}\right)_{2} \mathrm{P}(\mathrm{S}) \mathrm{NH}-\left(\mathrm{CH}_{2}\right)_{3}-\mathrm{HNP}(\mathrm{S})\left(\mathrm{OCH}_{2} \mathrm{CH}_{3}\right)_{2}$ & 90 & 75 & 20.17 & [18] \\
\hline 20 & $\left(\mathrm{CH}_{3} \mathrm{CH}_{2} \mathrm{O}\right)_{2} \mathrm{P}(\mathrm{S}) \mathrm{NH}-\mathrm{CH}_{2}-\mathrm{C}\left(\mathrm{CH}_{3}\right)_{2}-\mathrm{CH}_{2}-\mathrm{HNP}(\mathrm{S})\left(\mathrm{OCH}_{2} \mathrm{CH}_{3}\right)_{2}$ & 25 & - & 32.90 & [18] \\
\hline 21 & $\left(\mathrm{CH}_{3} \mathrm{CH}_{2} \mathrm{O}\right)_{2} \mathrm{P}(\mathrm{O}) \mathrm{NH}-\mathrm{CH}\left(\mathrm{CH}_{3}\right)-\mathrm{CH}_{2}-\mathrm{HNP}(\mathrm{O})\left(\mathrm{OCH}_{2} \mathrm{CH}_{3}\right)_{2}$ & 10 & - & 102.26 & [18] \\
\hline 22 & $\left(\mathrm{CH}_{3} \mathrm{CH}_{2} \mathrm{O}\right)_{2} \mathrm{P}(\mathrm{O}) \mathrm{NH}-\mathrm{CH}_{2}-\mathrm{C}\left(\mathrm{CH}_{3}\right)_{2}-\mathrm{CH}_{2}-\mathrm{HNP}(\mathrm{O})\left(\mathrm{OCH}_{2} \mathrm{CH}_{3}\right)_{2}$ & - & - & 174.21 & [18] \\
\hline 23 & $\left(\mathrm{CH}_{3} \mathrm{CH}_{2} \mathrm{O}\right)_{2} \mathrm{P}(\mathrm{O}) \mathrm{N}\left(\mathrm{C}_{4} \mathrm{H}_{8}\right) \mathrm{NP}(\mathrm{O})\left(\mathrm{OCH}_{2} \mathrm{CH}_{3}\right)_{2}$ & 10 & - & 127.31 & [18] \\
\hline
\end{tabular}




\begin{tabular}{|c|c|c|c|c|c|}
\hline 24 & $\left(\mathrm{CH}_{3} \mathrm{CH}_{2} \mathrm{O}\right)_{2} \mathrm{P}(\mathrm{O}) \mathrm{N}\left(\mathrm{C}_{6} \mathrm{H}_{10}\right) \mathrm{NP}(\mathrm{O})\left(\mathrm{OCH}_{2} \mathrm{CH}_{3}\right)_{2}$ & 65 & 30 & 25.17 & [18] \\
\hline 28 & $\left(\mathrm{C}_{6} \mathrm{H}_{5} \mathrm{O}\right)_{2} \mathrm{P}(\mathrm{O}) \mathrm{NH}-\left(\mathrm{CH}_{2}\right)_{2}-\mathrm{N}\left[\mathrm{P}(\mathrm{O})\left(\mathrm{OC}_{6} \mathrm{H}_{5}\right)_{2}\right] \mathrm{N}-\left(\mathrm{CH}_{2}\right)_{2}-\mathrm{HNP}(\mathrm{O})\left(\mathrm{OC}_{6} \mathrm{H}_{5}\right)_{2}$ & 50 & 10 & 95.11 & [19] \\
\hline 28 & $\left(\mathrm{C}_{6} \mathrm{H}_{5} \mathrm{O}\right)_{2} \mathrm{P}(\mathrm{O}) \mathrm{NH}-\left(\mathrm{CH}_{2}\right)_{2}-\mathrm{OP}(\mathrm{O})\left(\mathrm{OC}_{6} \mathrm{H}_{5}\right)_{2}$ & 40 & 10 & 104.70 & [19] \\
\hline 30 & $\left(\mathrm{C}_{6} \mathrm{H}_{5} \mathrm{O}\right)_{2} \mathrm{P}(\mathrm{O}) \mathrm{NH}-\mathrm{CH}\left(\mathrm{CH}_{3}\right)-\mathrm{CH}_{2}-\mathrm{HNP}(\mathrm{O})\left(\mathrm{OC}_{6} \mathrm{H}_{5}\right)_{2}$ & 85 & 85 & 18.88 & [19] \\
\hline 32 & $\left(\mathrm{C}_{6} \mathrm{H}_{5} \mathrm{O}\right)_{2} \mathrm{P}(\mathrm{O}) \mathrm{N}\left(\mathrm{CH}_{3}\right)-\left(\mathrm{CH}_{2}\right)_{2}-\left(\mathrm{CH}_{3}\right) \mathrm{NP}(\mathrm{O})\left(\mathrm{OC}_{6} \mathrm{H}_{5}\right)_{2}$ & 95 & 90 & 8.03 & [19] \\
\hline 33 & $\left(\mathrm{C}_{6} \mathrm{H}_{5} \mathrm{O}\right)_{2} \mathrm{P}(\mathrm{O}) \mathrm{NH}-\left(\mathrm{CH}_{2}\right)_{3}-\mathrm{HNP}(\mathrm{O})\left(\mathrm{OC}_{6} \mathrm{H}_{5}\right)_{2}$ & 40 & 10 & 99.46 & [19] \\
\hline 34 & $\left(\mathrm{C}_{6} \mathrm{H}_{5} \mathrm{O}\right)_{2} \mathrm{P}(\mathrm{O}) \mathrm{NH}-\mathrm{CH}_{2}-\mathrm{C}\left(\mathrm{CH}_{3}\right)_{2}-\mathrm{CH}_{2}-\mathrm{HNP}(\mathrm{O})\left(\mathrm{OC}_{6} \mathrm{H}_{5}\right)_{2}$ & 30 & - & 205.50 & [19] \\
\hline 35 & $\left(\mathrm{C}_{6} \mathrm{H}_{5} \mathrm{O}\right)_{2} \mathrm{P}(\mathrm{O}) \mathrm{NH}-\left(\mathrm{CH}_{2}\right)_{4}-\mathrm{HNP}(\mathrm{O})\left(\mathrm{OC}_{6} \mathrm{H}_{5}\right)_{2}$ & 10 & - & 163.99 & [19] \\
\hline 37 & $\left(\mathrm{C}_{6} \mathrm{H}_{5}\right)_{2} \mathrm{P}(\mathrm{O}) \mathrm{NH}-\mathrm{HNP}(\mathrm{O})\left(\mathrm{C}_{6} \mathrm{H}_{5}\right)_{2}$ & 50 & 10 & 86.46 & [19] \\
\hline 38 & $\left(\mathrm{C}_{6} \mathrm{H}_{5}\right)_{2} \mathrm{P}(\mathrm{O}) \mathrm{NH}-\left(\mathrm{CH}_{2}\right)_{2}-\mathrm{HNP}(\mathrm{O})\left(\mathrm{C}_{6} \mathrm{H}_{5}\right)_{2}$ & 60 & 15 & 252.62 & [19] \\
\hline 39 & $\left(\mathrm{C}_{6} \mathrm{H}_{5}\right)_{2} \mathrm{P}(\mathrm{O}) \mathrm{NH}-\mathrm{CH}\left(\mathrm{CH}_{3}\right)-\mathrm{CH}_{2}-\mathrm{HNP}(\mathrm{O})\left(\mathrm{C}_{6} \mathrm{H}_{5}\right)_{2}$ & 20 & - & 99.46 & [19] \\
\hline 40 & $\left(\mathrm{C}_{6} \mathrm{H}_{5}\right)_{2} \mathrm{P}(\mathrm{O}) \mathrm{N}\left(\mathrm{CH}_{3}\right)-\left(\mathrm{CH}_{2}\right)_{2}-\left(\mathrm{CH}_{3}\right) \mathrm{NP}(\mathrm{O})\left(\mathrm{C}_{6} \mathrm{H}_{5}\right)_{2}$ & 30 & - & 208.24 & [19] \\
\hline 41 & $\left(\mathrm{C}_{6} \mathrm{H}_{5}\right)_{2} \mathrm{P}(\mathrm{O}) \mathrm{NH}-\left(\mathrm{CH}_{2}\right)_{3}-\mathrm{HNP}(\mathrm{O})\left(\mathrm{C}_{6} \mathrm{H}_{5}\right)_{2}$ & 10 & - & 150.24 & [19] \\
\hline 42 & $\left(\mathrm{C}_{6} \mathrm{H}_{5}\right)_{2} \mathrm{P}(\mathrm{O}) \mathrm{NH}-\mathrm{CH}_{2}-\mathrm{C}\left(\mathrm{CH}_{3}\right)_{2}-\mathrm{CH}_{2}-\mathrm{HNP}(\mathrm{O})\left(\mathrm{C}_{6} \mathrm{H}_{5}\right)_{2}$ & 10 & - & 152.17 & [19] \\
\hline 43 & $\left(\mathrm{C}_{6} \mathrm{H}_{5}\right)_{2} \mathrm{P}(\mathrm{O}) \mathrm{NH}-\left(\mathrm{CH}_{2}\right)_{4}-\mathrm{HNP}(\mathrm{O})\left(\mathrm{C}_{6} \mathrm{H}_{5}\right)_{2}$ & 5 & - & 114.63 & [19] \\
\hline 44 & $\left(\mathrm{C}_{6} \mathrm{H}_{5}\right)_{2} \mathrm{P}(\mathrm{O}) \mathrm{N}\left(\mathrm{C}_{4} \mathrm{H}_{8}\right) \mathrm{NP}(\mathrm{O})\left(\mathrm{C}_{6} \mathrm{H}_{5}\right)_{2}$ & 10 & - & 151.23 & [19] \\
\hline 45 & $\left(\mathrm{C}_{6} \mathrm{H}_{5}\right)_{2} \mathrm{P}(\mathrm{O}) \mathrm{NH}\left(\mathrm{C}_{6} \mathrm{H}_{10}\right) \mathrm{HNP}(\mathrm{O})\left(\mathrm{C}_{6} \mathrm{H}_{5}\right)_{2}$ & 60 & 20 & 20.18 & [19] \\
\hline 47 & $\left(\mathrm{C}_{6} \mathrm{H}_{5}\right)_{2} \mathrm{P}(\mathrm{O}) \mathrm{O}-\left(\mathrm{CH}_{2}\right)_{2}-\mathrm{OP}(\mathrm{O})\left(\mathrm{C}_{6} \mathrm{H}_{5}\right)_{2}$ & 5 & - & 184.11 & [19] \\
\hline 49 & $\left(\mathrm{C}_{4} \mathrm{H}_{8} \mathrm{~N}\right)_{2} \mathrm{P}(\mathrm{O}) \mathrm{NH}\left(\mathrm{C}_{6} \mathrm{H}_{6}\right) \mathrm{NHP}(\mathrm{O})\left(\mathrm{NC}_{4} \mathrm{H}_{8}\right)$ & 80 & 30 & 18.53 & [19] \\
\hline 50 & $\left(\mathrm{C}_{5} \mathrm{H}_{10} \mathrm{~N}\right)_{2} \mathrm{P}(\mathrm{O}) \mathrm{NH}\left(\mathrm{C}_{6} \mathrm{H}_{6}\right) \mathrm{NHP}(\mathrm{O})\left(\mathrm{NC}_{5} \mathrm{H}_{10}\right)$ & 100 & 95 & 6.15 & [19] \\
\hline 51 & $\left(\mathrm{C}_{6} \mathrm{H}_{12} \mathrm{~N}\right)_{2} \mathrm{P}(\mathrm{O}) \mathrm{NH}\left(\mathrm{C}_{6} \mathrm{H}_{6}\right) \mathrm{NHP}(\mathrm{O})\left(\mathrm{NC}_{6} \mathrm{H}_{12}\right)$ & 85 & 40 & 27.22 & [19] \\
\hline
\end{tabular}

In the second bioassay, only the toxicities of four compounds were evaluated on last instar larvae (Table 2). Among these compounds, compound 50 with the lowest $\mathrm{I}_{50}$ has revealed the best insecticidal properties as the $\mathrm{LC}_{50}$ of it was lesser.

Table 2. Susceptibility of last larval instar of X. luteola to temephos derivative compounds after $24 \mathrm{~h}$.

\begin{tabular}{|c|c|c|c|c|}
\hline Compounds & $\begin{array}{l}\text { Number of treated } \\
\text { larvae }\end{array}$ & $\begin{array}{c}\mathrm{LC}_{50} \\
(\mathrm{mg} / \mathrm{l})(95 \% \\
\text { confidence limit })\end{array}$ & Slope \pm SE & $X^{2}(d f)$ \\
\hline 19 & 250 & $\begin{array}{c}1423.05 \\
(998.06-1858.05)\end{array}$ & $1.19 \pm 0.31$ & $1.87(2)$ \\
\hline 30 & 250 & $\begin{array}{c}1230.40 \\
(931.16-1663.17)\end{array}$ & $1.84 \pm 0.3$ & $1(2)$ \\
\hline 32 & 250 & $\begin{array}{c}952.61 \\
(621.13-1015.44)\end{array}$ & $1.78 \pm 0.29$ & $0.07(2)$ \\
\hline 50 & 250 & $\begin{array}{c}511.47 \\
(341.26-674.06)\end{array}$ & $1.9 \pm 0.3$ & $1.5(2)$ \\
\hline
\end{tabular}


As these compounds affected AChE and general esterases, so the activities of these enzymes were determined in the larvae treated with different concentrations (Fig. 2).
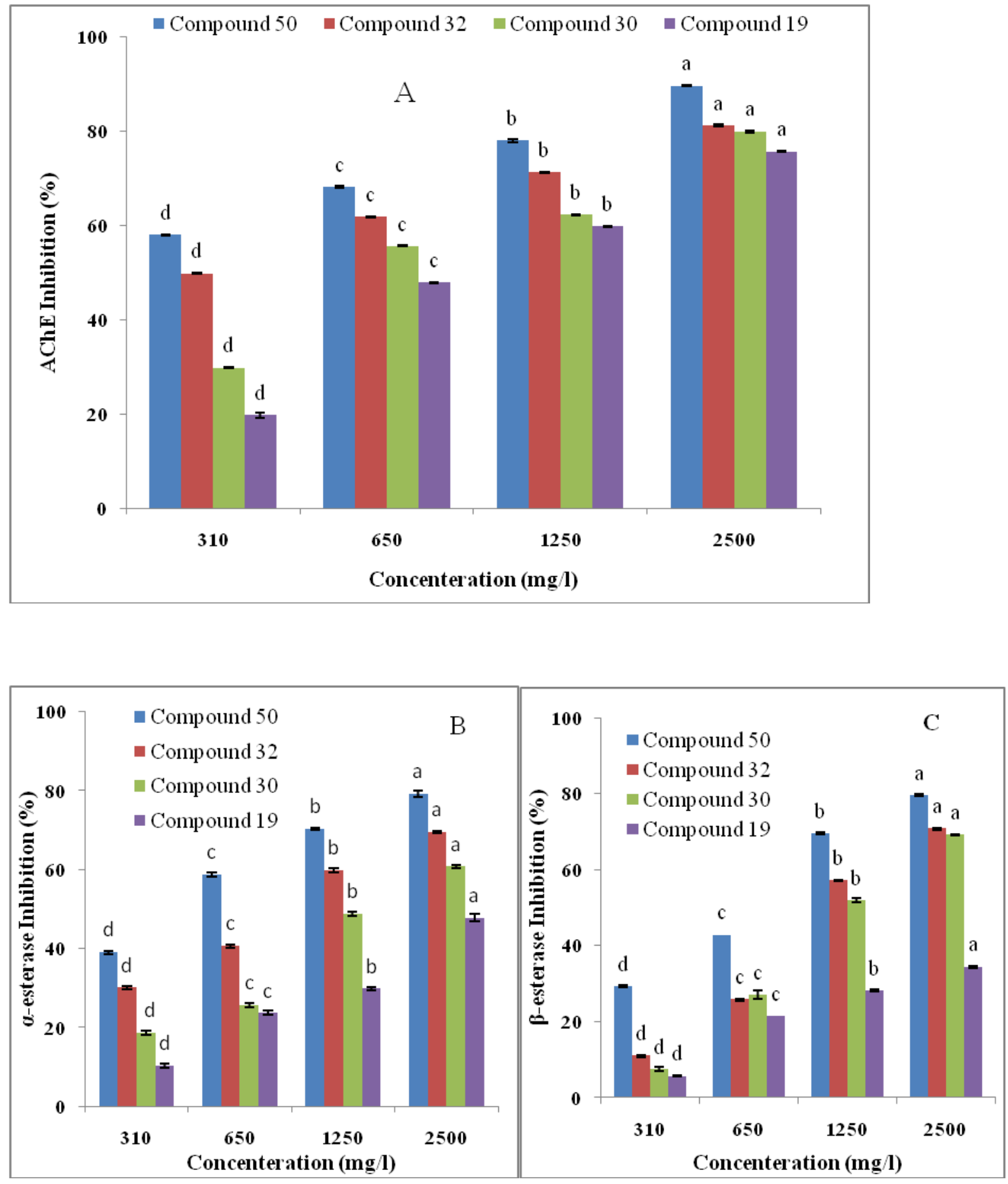
Fig. 2. Inhibition (\%) of $\mathrm{AChE}(\mathrm{A}), \alpha$ - esterase (B) and $\beta$ - esterase (C) form third instar larvae treated with different concentrations in vivo conditions. The inhibition percentage was calculated as follow: [(activity in control activity in treated insect)/activity in control] $* 100$.

* Means followed by different letters within columns indicate significant differences between concentrations, Tukey's test $(p<0.05)$.

\subsection{AChE purification}

Some non target serine esterases, the carboxylesterases, confer protection against toxicants. Sometimes, these protective esterases are sensitive to inhibition by organophosphates, and at some cases, even more sensitive than the AChE at target site. These enzymes demonstration limited kinetic efficiency and serves as pesticide sequestration. With the use of chromatography, the impurities in homogenate crude were easily removed from the extraction sample. Due to inhibition of general esterases by temephos derivative compounds, the AChE was purified using affinity chromatography. Therefore, in gathering of information regarding the effect of temephos derivative compounds on the AChE, it has been purified by affinity chromatography and the results obtained were summarized in Table 3 and Fig. 3. As shown in table 3, AChE has been purified up to 75.29 times.

Table 3. Purification of AChE from X. luteola by procainamide- based affinity chromatography

\begin{tabular}{|c|c|c|c|c|c|c|c|}
\hline $\begin{array}{c}\text { Purification } \\
\text { steps }\end{array}$ & $\begin{array}{c}\text { Total } \\
\text { Volu } \\
\text { me } \\
(\mathrm{ml})\end{array}$ & $\begin{array}{c}\text { Protein } \\
(\mathrm{mg} / \mathrm{ml} \\
)\end{array}$ & $\begin{array}{l}\text { Total } \\
\text { protein } \\
(\mathrm{mg})\end{array}$ & $\begin{array}{c}\text { Specific } \\
\text { activity } \\
(\mu \mathrm{mol} / \mathrm{min} / \mathrm{mg} \\
\text { protein) }\end{array}$ & $\begin{array}{c}\text { Total } \\
\text { activity } \\
\text { ( } \mu \mathrm{mol} / \mathrm{min})\end{array}$ & (\%) Product & $\begin{array}{l}\text { Purifica } \\
\text { tion factor }\end{array}$ \\
\hline $\begin{array}{c}\text { Affinity } \\
\text { chromatography }\end{array}$ & 2 & 0.015 & 0.03 & 15.36 & 0.461 & 8.51 & 75.29 \\
\hline
\end{tabular}




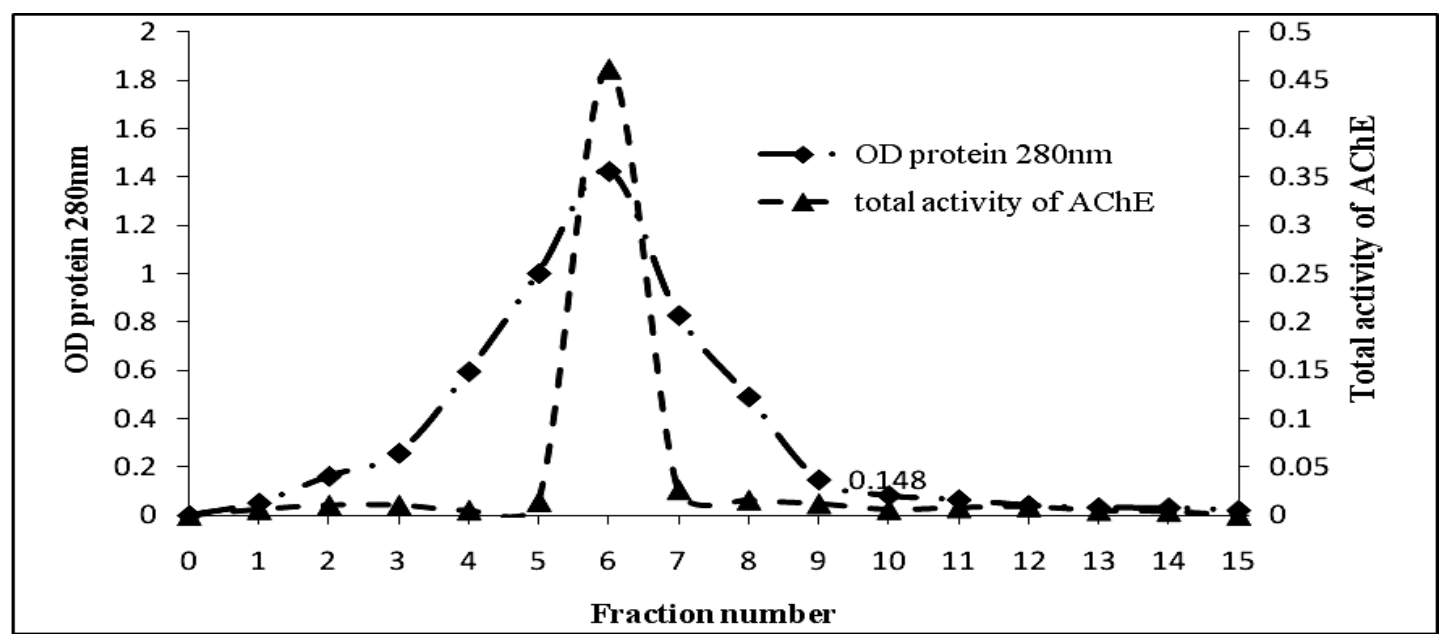

Fig. 3. Distribution pattern of protein and AChE activity over the fractions obtained following the affinity chromatography of crude enzyme. Fraction no. 6.0 contained the highest enzymatic activity using ATCHI as the substrate.

To determine the molecular weight of purified enzyme, sample was charged in SDSelectrophoresis gel accompanied by protein marker. The single band was detected in the gel and the molecular mass of the purified AChE was calculated $70 \mathrm{kD}$ (Fig.4).

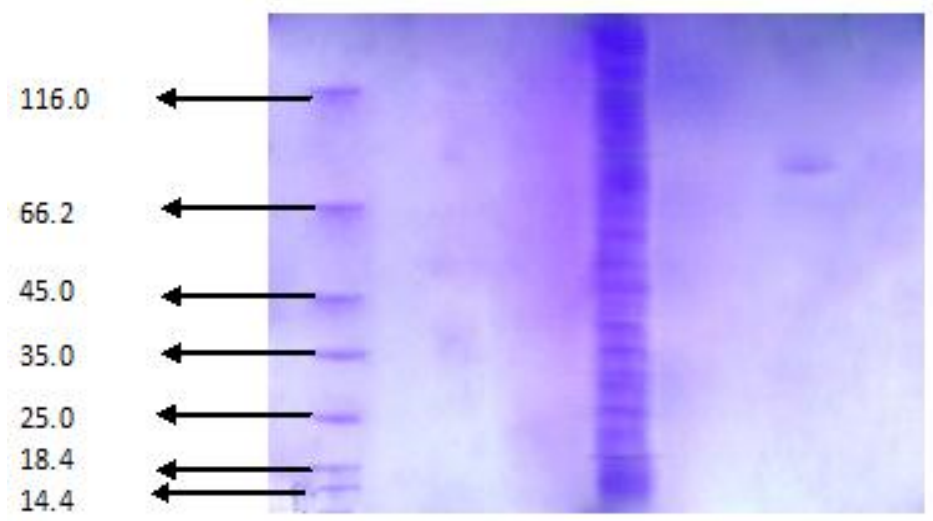

Fig.4. The SDS-PAGE of AChE purification from X. luteola.

Marker; crude extract; affinity chromatography, respectively.

\subsubsection{PH and temperature effects on AChE activity}

The effects of $\mathrm{pH}$ on AChE activity purified from X. luteola showed high peak at $\mathrm{pH} 7.0$ (Fig.

5). Significant difference in the AChE activity was found between the pHs 6.0, 7.0 and 8.0. In 
higher or lower than optimal $\mathrm{pH}$, enzyme activity decreased significantly and at $\mathrm{pH} 10$ was decreased to less than $30 \%$. AChE exhibited the most activity at $35{ }^{\circ} \mathrm{C}$ and approximately $70 \%$ of its activity was maintained at $45{ }^{\circ} \mathrm{C}$. In other temperatures examined in this research, enzyme activity was reduced to less than $20 \%$.
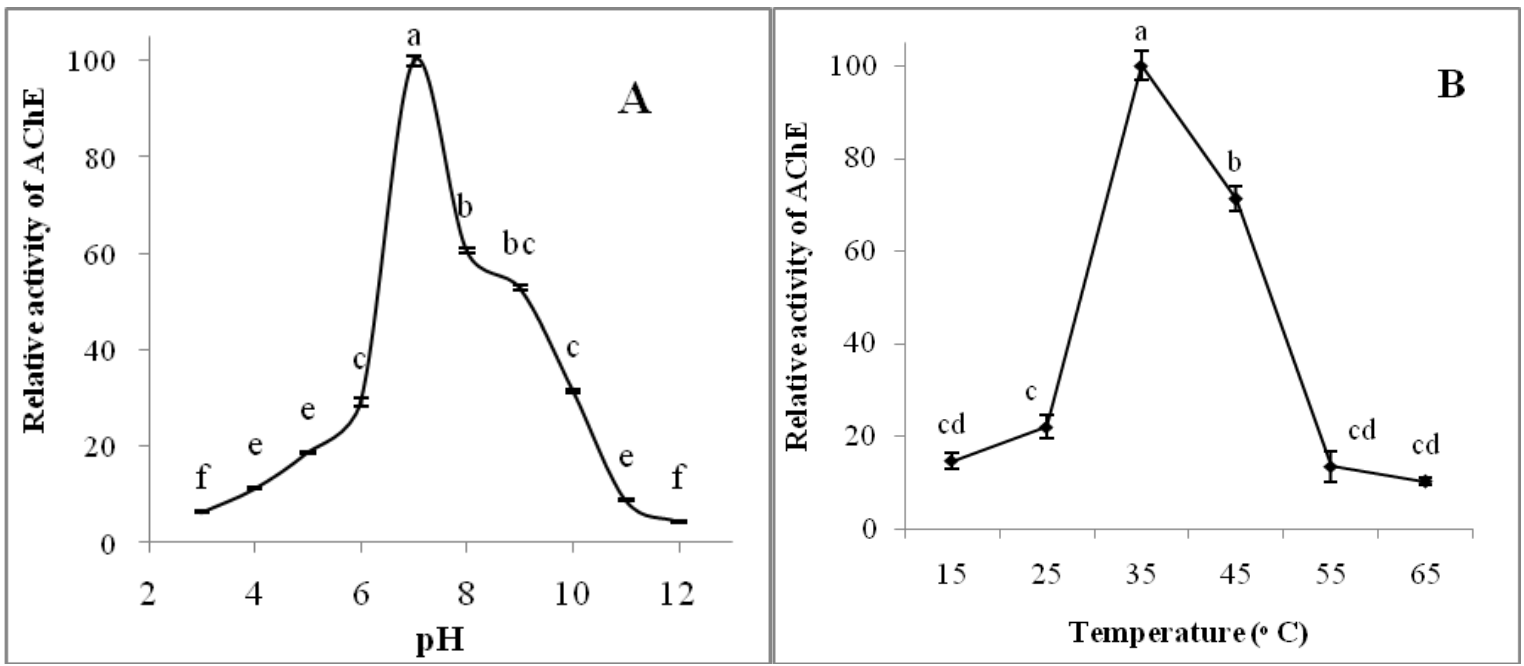

Fig. 5. The effect of pHs (A) and temperatures (B) on the mean relative activities of AChE purified from $X$. luteola

Different letters indicate that the activity of enzyme in different $\mathrm{pH}$ are significantly different from each other by Tukey's test $(p<0.05)$.

\subsubsection{Determination of $I_{50}$, kinetic parameters and mechanism of inhibition}

Inhibitory effects of temephos derivatives on purified enzyme were examined and median inhibition concentrations were expressed in Table 4 using the crude extract and purified AChE as enzyme source.

Table 4. Inhibitory effect ( $\mathrm{IC}_{50}$ values) of different inhibitors on crude extract and purified AChE from X. luteola

\begin{tabular}{ccc}
\hline \multirow{2}{*}{ Compound } & $\mathbf{I}_{\mathbf{5 0}}$ of crude $(\mathbf{9 5 \%}$ confidence limit) & $\begin{array}{c}\mathbf{I}_{\mathbf{5 0}} \text { of purified enzyme }(\mathbf{9 5 \%} \text { confidence limit) } \\
\mathbf{~} \mathbf{m g} / \mathbf{l}\end{array}$ \\
\hline $\mathbf{1 9}$ & $20.17(16.10-25.36)$ & $9.19(8.01-12.31)$ \\
$\mathbf{3 0}$ & $18.88(16.43-20.54)$ & $6.24(3.50-6.94)$ \\
$\mathbf{3 2}$ & $8.03(6.99-9.66)$ & $2.96(1.08-3.46)$ \\
$\mathbf{5 0}$ & $6.15(5.63-8.22)$ & $2.02(1.55-3.78)$ \\
\hline
\end{tabular}

The ratio of $\mathrm{I}_{50}$ of crude extracts to $\mathrm{I}_{50}$ of purified enzyme was $2.19,2.9,2.17$ and 3.40 for the compound No. 19, 30, 32 and 50, respectively. The insect general esterases are sensitive to inhi- 
bition by organophosphates and also, these enzymes hydrolyze the acetylthiocholine iodide, AChE substrate. These reasons can explain the differences in $\mathrm{I}_{50} \mathrm{~S}$ obtained by crude extract and purified AchE. The effect of two concentrations of compounds, i.e. $\mathrm{I}_{25}$ and $\mathrm{I}_{50}$, are examined on AChE activity in order to determine the type of inhibitory mechanisms and kinetic parameters are determined for each of them by Hyper software. With regard to these parameters, inhibition type and $\mathrm{K}_{\mathrm{i}}$ of inhibitors were calculated and the results were presented in Table 5.

Table 5. Kinetic parameters and inhibitory effect of IC25 and $\mathrm{IC}_{50}$ of temeohos derivatives on the AChE purified from X. luteola

\begin{tabular}{|c|c|c|c|c|}
\hline Compounds & & $\begin{array}{c}\mathbf{K}_{\mathrm{m}}^{\text {app }} \\
\mu \mathrm{M}\end{array}$ & $\begin{array}{c}V_{\max }{ }^{\text {app }} \\
\mu \mathrm{m} / \mathrm{min} / \mathrm{mg} \text { protein }\end{array}$ & $\begin{array}{l}\mathbf{K}_{\mathrm{i}} \\
\mu \mathbf{M}^{-1} \min ^{-1}\end{array}$ \\
\hline & control & $60.19 \pm 1.32$ & $52.40 \pm 1.18$ & - \\
\hline 19 & $\begin{array}{l}\mathrm{IC}_{25} \\
\mathrm{IC}_{50}\end{array}$ & $\begin{array}{c}135.12 \pm 2.21 \\
94.74 \pm 1.38\end{array}$ & $\begin{array}{l}39.87 \pm 1.54 \\
20.09 \pm 2.22\end{array}$ & 0.625 \\
\hline 30 & $\begin{array}{l}\mathrm{IC}_{25} \\
\mathrm{IC}_{50}\end{array}$ & $\begin{array}{c}95.62 \pm 2.4 \\
72.04 \pm 0.73\end{array}$ & $\begin{array}{l}30.37 \pm 1.67 \\
16.15 \pm 1.05\end{array}$ & 1.04 \\
\hline 32 & $\begin{array}{l}\mathrm{IC}_{25} \\
\mathrm{IC}_{50}\end{array}$ & $\begin{array}{l}99.05 \pm 1.58 \\
65.76 \pm 1.70\end{array}$ & $\begin{array}{l}25.21 \pm 2.34 \\
12.29 \pm 0.74\end{array}$ & 3.69 \\
\hline 50 & $\begin{array}{l}\mathrm{IC}_{25} \\
\mathrm{IC}_{50}\end{array}$ & $\begin{array}{l}89.83 \pm 2.52 \\
64.81 \pm 1.03 \\
\end{array}$ & $\begin{array}{l}19.92 \pm 1.12 \\
10.79 \pm 0.85 \\
\end{array}$ & 4.70 \\
\hline
\end{tabular}

\subsection{QSAR analysis of Temephos derivatives}

Different quantum chemical properties as biological and affiliates descriptor were calculated using Gaussian software and $\log \left(1 / \mathrm{LC}_{50}\right)$ parameter, are presented in Table 6.

Table 6. Quantum-chemical and theoretical descriptors for compounds computed by Gaussian 03 program.

\begin{tabular}{|c|c|c|c|c|c|c|c|c|c|c|c|c|}
\hline \multirow{3}{*}{ No. } & \multicolumn{9}{|c|}{ Electronic descriptors } & \multicolumn{2}{|c|}{$\begin{array}{c}\text { Structural descrip- } \\
\text { tors }\end{array}$} & \multirow{3}{*}{$\log \left(1 / \mathbf{I}_{50}\right)$} \\
\hline & \multicolumn{4}{|c|}{ Charge } & \multicolumn{2}{|c|}{ Polarizability } & \multicolumn{3}{|c|}{ Frontier molecular orbital } & \multirow{2}{*}{$\begin{array}{c}\text { Lipoph. } \\
\mu \\
\text { (Debye) } \\
\end{array}$} & \multirow{2}{*}{$\begin{array}{c}\text { Steric } \\
M v\end{array}$} & \\
\hline & $\begin{array}{l}Q_{\mathbf{P}(1)} \\
(\mathbf{a . u})\end{array}$ & $\begin{array}{l}Q_{\mathbf{P}(2)} \\
(\mathbf{a . u})\end{array}$ & $\begin{array}{c}Q_{\mathbf{X}} \\
(\text { a.u) }\end{array}$ & $\begin{array}{c}Q_{\mathrm{N}} \\
(\mathbf{a} . \mathbf{u})\end{array}$ & $P L_{\mathrm{P}=\mathrm{X}}$ & $P L_{\mathrm{N}-\mathrm{H}}$ & $E_{\text {номо }}$ & $E_{\text {LUMO }}$ & $\omega$ & & & \\
\hline 9 & 2.341 & 2.482 & -1.112 & -1.343 & 3.453 & 1.819 & -0.252 & -0.031 & 0.090 & 6.153 & 443.414 & -1.95 \\
\hline 6 & 2.399 & 2.481 & -1.120 & -1.346 & 3.519 & 1.795 & -0.242 & -0.030 & 0.087 & 8.545 & 300.932 & -2.06 \\
\hline 10 & 2.342 & 2.482 & -1.117 & -1.343 & 3.459 & 1.817 & -0.247 & -0.031 & 0.089 & 7.874 & 385.289 & -1.88 \\
\hline 12 & 1.995 & 1.993 & -0.669 & -1.018 & 2.664 & 1.448 & -0.249 & -0.011 & 0.142 & 2.640 & 257.626 & -2.27 \\
\hline 13 & 1.995 & 1.997 & -0.673 & -1.016 & 2.670 & 1.446 & -0.248 & -0.011 & 0.141 & 3.687 & 246.621 & -2.27 \\
\hline 14 & 2.015 & 2.016 & -0.657 & -0.893 & 2.673 & ---- & -0.243 & -0.005 & 0.128 & 3.927 & 277.857 & -1.85 \\
\hline 15 & 2.002 & 2.002 & -0.670 & -1.015 & 2.672 & 1.438 & -0.249 & -0.006 & 0.133 & 6.528 & 234.969 & -1.99 \\
\hline
\end{tabular}




\begin{tabular}{|c|c|c|c|c|c|c|c|c|c|c|c|c|}
\hline 16 & 2.007 & 2.009 & -0.682 & -1.021 & 2.691 & 1.445 & -0.248 & -0.011 & 0.141 & 1.981 & 302.083 & -1.53 \\
\hline 17 & 2.005 & 2.008 & -0.681 & -1.016 & 2.689 & 1.443 & -0.246 & -0.010 & 0.138 & 6.738 & 250.477 & -2.22 \\
\hline 18 & 2.026 & 2.028 & -0.665 & -0.895 & 2.693 & ---- & -0.241 & -0.006 & 0.065 & 1.585 & 345.518 & -1.72 \\
\hline 19 & 2.002 & 2.020 & -0.679 & 1.032 & 2.879 & 1.453 & -0.249 & -0.005 & 0.132 & 8.640 & 334.661 & -0.91 \\
\hline 20 & 2.000 & 2.021 & -0.663 & -1.054 & 2.684 & 1.494 & -0.247 & -0.010 & 0.069 & 8.427 & 301.243 & -1.50 \\
\hline 21 & 2.470 & 2.472 & -1.120 & -1.031 & 3.592 & 1.453 & -0.269 & -0.008 & 0.147 & 7.228 & 284.028 & -2.30 \\
\hline 22 & 2.473 & 2.491 & -1.128 & -1.050 & 3.619 & 1.502 & -0.259 & -0.007 & 0.070 & 13.056 & 262.414 & -2.40 \\
\hline 23 & 2.481 & 2.481 & -1.074 & -0.892 & 3.555 & ---- & -0.248 & -0.006 & 0.066 & 0.055 & 260.397 & -2.10 \\
\hline 24 & 2.476 & 2.476 & -1.121 & -1.012 & 3.597 & 1.428 & -0.266 & -0.004 & 0.139 & 5.611 & 256.666 & -1.41 \\
\hline 28 & 2.457 & 2.465 & -1.093 & -1.021 & 3.560 & 1.453 & -0.257 & -0.031 & 0.091 & 6.428 & 322.689 & -1.97 \\
\hline 28 & 2.462 & 2.545 & -1.090 & -1.007 & 3.635 & 1.433 & -0.260 & -0.031 & 0.092 & 7.434 & 305.300 & -2.01 \\
\hline 30 & 2.465 & 2.466 & -1.098 & -1.026 & 3.559 & 1.451 & -0.256 & -0.031 & 0.091 & 6.492 & 319.661 & -1.03 \\
\hline 32 & 2.472 & 2.485 & -1.095 & -0.878 & 3.580 & ---- & -0.213 & -0.057 & 0.116 & 6.097 & 406.507 & -0.78 \\
\hline 33 & 2.467 & 2.477 & -1.090 & -1.010 & 3.567 & 1.439 & -0.256 & -0.030 & 0.090 & 8.430 & 379.314 & -1.99 \\
\hline 34 & 2.467 & 2.477 & -1.109 & -1.050 & 3.586 & 1.502 & -0.254 & -0.031 & 0.091 & 7.761 & 341.167 & -2.13 \\
\hline 35 & 2.458 & 2.467 & -1.094 & -1.015 & 3.561 & 1.435 & -0.255 & -0.030 & 0.091 & 4.123 & 380.173 & -2.21 \\
\hline 37 & 2.032 & 2.032 & -1.119 & -0.800 & 3.151 & 1.196 & -0.265 & -0.058 & 0.126 & 6.179 & 275.395 & -1.93 \\
\hline 38 & 2.030 & 2.049 & -1.082 & -1.012 & 3.112 & 1.417 & -0.257 & -0.055 & 0.120 & 8.542 & 327.663 & -2.40 \\
\hline 39 & 2.120 & 2.133 & -1.084 & ---- & 3.193 & ---- & -0.266 & -0.058 & 0.126 & 5.386 & 369.664 & -2.26 \\
\hline 40 & 2.037 & 2.049 & -1.085 & -1.010 & 3.122 & 1.424 & -0.256 & -0.054 & 0.120 & 7.277 & 340.937 & -1.99 \\
\hline 41 & 2.053 & 2.067 & -1.086 & -0.868 & 3.139 & ---- & -0.246 & -0.055 & 0.118 & 4.265 & 370.064 & -2.31 \\
\hline 42 & 2.054 & 2.056 & -1.120 & -1.017 & 3.139 & 1.479 & -0.257 & -0.056 & 0.122 & 11.497 & 367.251 & -2.17 \\
\hline 43 & 2.056 & 2.061 & -1.121 & -0.016 & 3.136 & 1.474 & -0.255 & -0.056 & 0.121 & 10.918 & 428.576 & -2.18 \\
\hline 44 & 2.051 & 2.056 & -1.065 & -1.009 & 3.112 & 1.409 & -0.256 & -0.047 & 0.110 & 2.040 & 406.652 & -1.82 \\
\hline 45 & 2.071 & 2.071 & -1.068 & -0.874 & 3.139 & ---- & -0.244 & -0.049 & 0.110 & 0.268 & 382.940 & -1.18 \\
\hline 47 & 2.047 & 2.051 & -1.088 & -1.056 & 3.135 & 1.412 & -0.251 & -0.055 & 0.119 & 13.328 & 359.233 & -1.30 \\
\hline 49 & 2.371 & 2.375 & -1.078 & -0.967 & 3.455 & 0.973 & -0.196 & -0.018 & 0.064 & 7.202 & 398.202 & -1.26 \\
\hline 50 & 2.365 & 2.369 & -1.084 & -0.970 & 3.453 & 1.385 & -0.198 & -0.019 & 0.065 & 7.139 & 351.385 & -1.01 \\
\hline 51 & 2.363 & 2.371 & -1.092 & -0.989 & 3.463 & 1.388 & -0.195 & -0.017 & 0.065 & 6.585 & 491.352 & -1.43 \\
\hline
\end{tabular}

The next step is that the equation was calculated based on the relationship between structureactivity of temephos derivatives and inhibition of $\mathrm{AChE}$ from elm leaf beetle.

$$
\begin{aligned}
& \mathrm{p}\left(\mathrm{IC}_{50}\right)=-2.436 \mathrm{Q}_{\mathrm{P}(1)}-2.191 \mathrm{Q}_{\mathrm{P}(2)}+3.754 Q_{X}+0.071 Q_{N}+4.333 P L_{P=X} \\
& +0.138 P L_{N-H}+9.879 E_{H O M O}+2.087 E_{L U M O}-1.047 \omega-0.014 \mu+0.001 M v-0.748 \\
& n=36 ; R^{2}=0.419 ; R_{A d j}^{2}=0.430 ; S_{\text {reg }}=0.429 ; r=0.637, F_{\text {statistic }}=1.112
\end{aligned}
$$

In this equation the $\mathrm{R}^{2}$ was high and regression error, $\mathrm{r}$ and the VIF were low, which signifies that the alignment error had been between independent descriptors. That is why PCA was use to eliminate this error.

$$
\begin{aligned}
& P C 1=0.442 \mathrm{Q}_{\mathrm{P}(1)}+0.447 \mathrm{Q}_{\mathrm{P}(2)}-0.409 Q_{X}-0.166 Q_{N}+0.472 P L_{P=X} \\
& +0.100 E_{H O M O}-0.091 E_{L U M O}-0.304 \omega+0.24848 \mu+0.314 M v \\
& P C 2=-0.230 \mathrm{Q}_{\mathrm{P}(1)}-0.217 \mathrm{Q}_{\mathrm{P}(2)}-0.324 Q_{X}+0.273 Q_{N}+0.02 P L_{P=X} \\
& -0.559 E_{\text {HOMO }}-0.656 E_{L U M O}+0.211 \omega+0.164 \mu+0.185 M v
\end{aligned}
$$

These two components have 43.58 , and $25.08 \%$ of the total variance accounted for $100 \%$ of the variance. Therefore, the result of the above equation is that electron variables will have 
greater effect than structural variables on the dependent descriptor. Based on the above described equation, the $\mathrm{PL}_{\mathrm{N}-\mathrm{H}}$ of modifiers will be eliminated, because the ratio is lower than 2.0. As such, the equation between the structures and biological activity will be achieved.

$$
\begin{aligned}
& \mathrm{p}\left(\mathrm{IC}_{50}\right)=-1.870 \mathrm{Q}_{\mathrm{P}(1)}-2.071 \mathrm{Q}_{\mathrm{P}(2)}+4.997 Q_{X}+0.029 Q_{N}+4.502 P L_{P=X} \\
& +12.402 E_{H O M O}-5.767 E_{L U M O}+1.337 \omega-0.008 \mu+0.001 M v-0.069 \\
& n=36 ; R^{2}=0.615 ; S_{\text {reg }}=0.407 ; r=0.525, F_{\text {statistic }}=2.011
\end{aligned}
$$

The equation also has high linearity error tolerance in order to eliminate this error. Descriptors $\mathrm{PL}_{\mathrm{P}}=\mathrm{x}$ and $\mathrm{Q}_{\mathrm{P}(1)}$ which has a high VIF is also removed and 8, 24 and 34 of the compounds were deleted and the following equation was obtained.

$$
\begin{aligned}
& \mathrm{p}\left(\mathrm{IC}_{50}\right)=0.830 \mathrm{Q}_{\mathrm{P}(2)}+1.392 Q_{X}+0.398 Q_{N}+14.961 E_{\text {номо }} \\
& -11.798 E_{\text {LUMO }}-1.927 \omega-0.004 \mu+0.001 M v+1.471 \\
& n=33 ; R^{2}=0.892 ; S_{\text {reg }}=0.315 ; r=0.225, F_{\text {statistic }}=3.121
\end{aligned}
$$

Table 7. VIF ${ }^{\mathrm{a}}$ values of experimental and theoretical QSAR equations

\begin{tabular}{cccc}
\hline Independent variables & Eq. 1 & Eq. 3 & Eq. 4 \\
\hline $\mathbf{Q}_{\mathbf{P}(\mathbf{1}) \cdot}$ & 112.856 & 103.660 & - \\
$\mathbf{Q}_{\mathbf{P}(\mathbf{2})}$ & 124.675 & 69.200 & 4.589 \\
$\mathbf{Q}_{\mathbf{X}}$ & 81.905 & 76.640 & 7.784 \\
$\mathbf{Q}_{\mathbf{N}}$ & 4.525 & 3.592 & 1.320 \\
$\mathbf{P L}_{\mathbf{P}=\mathbf{X}}$ & 308.119 & 294.236 & - \\
$\mathbf{P L}_{\mathbf{N}-\mathbf{H}}$ & 3.385 & - & - \\
$\mathbf{E}_{\mathbf{H O M O}}$ & 3.333 & 1.888 & 1.340 \\
$\mathbf{E}_{\mathbf{L U M O}}$ & 7.537 & 4.589 & 5.989 \\
$\mathbf{\omega}$ & 3.921 & 1.947 & 2.003 \\
$\boldsymbol{\mu}$ & 1.853 & 1.242 & 1.197 \\
$\mathbf{M v}$ & 3.444 & 2.990 & 2.332 \\
\hline
\end{tabular}

a VIF $=1 /\left(1_{-} R_{i}^{2}\right)$; where, Ri is the multiple correlation coefficient of the ith independent variable on all of the other independent variables. 
One of the best statistical methods to communicate internally between independent variables and AChE inhibited compounds is correlation matrix that is presented in the table 8 . Some of the regression coefficients were close to 0.70 , showing that they were closely correlated. The evaluation of the correlation coefficient of $E_{\mathrm{HOMO}}$ versus $\mu(\mathrm{r}=-0.61)$ shows that $E_{\mathrm{HOMO}}$ has the higher contribution to the dipole moment descriptor; this implies that the frontier molecular orbital controlled process plays a very important function in the interaction of the compounds with insect AChE. Thus, decreasing the energy of the HOMO can greatly increase the $\mu$ and subsequently the value of $\mathrm{P}\left(\mathrm{IC}_{50}\right)$.

Table 8. Correlation matrix for $\mathrm{p}(\mathrm{IC} 50)$ and selected parameters in eqn (4)

\begin{tabular}{|c|c|c|c|c|c|c|c|c|}
\hline & $\mathbf{Q}_{\mathbf{P}(2)}$ & $\mathbf{Q}_{\mathbf{x}}$ & $\mathbf{Q}_{\mathbf{N}}$ & $\mathbf{E}_{\text {HOMO }}$ & $\mathbf{E}_{\text {LUMO }}$ & $\omega$ & $\mu$ & Mv \\
\hline $\mathbf{Q}_{\mathbf{P}(2)}$ & 1.000 & & & & & & & \\
\hline $\mathbf{Q}_{\mathbf{X}}$ & -0.62 & 1.000 & & & & & & \\
\hline $\mathbf{Q}_{\mathbf{N}}$ & -0.31 & 0.23 & 1.000 & & & & & \\
\hline $\mathbf{E}_{\text {номо }}$ & 0.19 & 0.16 & -0.01 & 1.000 & & & & \\
\hline $\mathbf{E}_{\text {Lumo }}$ & 0.05 & 0.41 & 0.15 & 0.12 & 1.000 & & & \\
\hline$\omega$ & -0.57 & 0.34 & 0.24 & 0.17 & -0.12 & 1.000 & & \\
\hline $\boldsymbol{\mu}$ & 0.15 & -0.33 & 0.51 & -0.61 & -0.23 & -0.05 & 1.000 & \\
\hline Mv & 0.2 & -0.51 & 0.08 & 0.25 & -0.58 & -0.26 & 0.11 & 1.000 \\
\hline
\end{tabular}

\section{Discussion}

\subsection{The effect of compound on AChE and detoxification enzyme}

Temephos is one of the renowned insecticides belonging to bis-phosphate family (Fig. 6). It is a non-systematic insecticide recommended for the control of a wide range of pests [28]

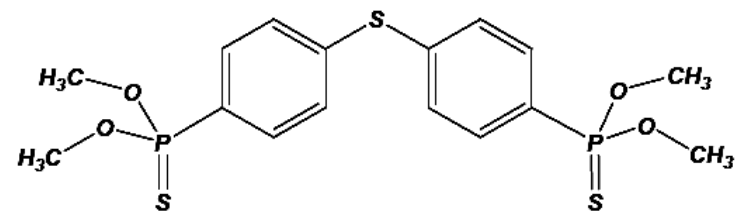

Fig. 6. Chemical structure of temephos 
Due to the side effects, costly and time-consuming for the synthesis of new insecticide, it is necessary to find a suitable alternative compound for their replacement [29]. We recommend the designing and synthesis of new derivatives of the phosphate, in hopes of finding a compound with the lowest side effects and best insecticidal properties. The result indicated that all compounds could inhibit AChE activity more than the other enzymes, since the AChE is the key target for these compounds. Measuring enzyme's activities in treated larvae show that compound 50 exhibited higher inhibitory effect than other compounds. The most potent inhibitor to the least was $\mathbf{5 0}>\mathbf{3 2}>\mathbf{3 0}>\mathbf{1 9}$, as indicated by the relative enzyme activity values (Figs. 2), which show that AChE and general esterases are inhibited by these inhibitors. The in vivo inhibition results were dose dependent. This implies that increasing the concentration of inhibitors will decrease the enzymes activities. Esterases are the detoxification enzymes in insect which hydrolysis the external and internal compounds by adding a water molecule. These enzymes sequester or degrade insecticide esters before they get to their target sites on the nervous system [30].

\subsection{Biochemistry of purified AChE}

Some attempts have been made to purify or characterize the Insect's AChEs, and consequently, various information regarding their biochemical properties are currently available $[5 ; 6 ; 7 ; 21$; $31 ; 32 ; 33 ; 34]$. In most cases, the affinity chromatography was employed for purifying this enzyme in some insects and the various isoforms with different molecular weights were detected by reducing and non-reducing gel electrophoresis. These insects typically have 2 or 3 isoforms in non-reduction gel with molecular weight between 130-140 KDa and one or more subunit in reduction gel with molecular weight between 60-94 KDs. In majority of these species, purification percentage during purification activity has been calculated above $200 \%$. Thus, the SDS-PAGE analysis showed a single $70 \mathrm{kDa}$ band for $X$. luteola as has been reported in the AChEs of other 
insects. Therefore, the molecular weight of the AChE was nearly the same as those purified from Drosophila melanogaster (56 kDa) [35], Haematobia irritans (54 kDa) [36], Leptinitarsa decemlineata (65 kDa) [32; 37], Rhyzopertha dominica (56 kDa) [38; 39], Galeria melonella (60 kDa) [33], Schizaphis graminum (72 kDa) [21] and Aphis gossypii (63.5 kDa) [4].

Optimal $\mathrm{pH}$ for insect AChE activities was reported as 6 to 9.0. Activity of AChE purified from houseflies revealed high activities at $\mathrm{pHs} 7-9$ [40], while the optimum $\mathrm{pH}$ for $\mathrm{AChE}$ purified from cotton aphid (A. gossypii) was 7.2 [4]. Activity of AChE in housefly increases with increase in temperature from 20 to $45{ }^{\circ} \mathrm{C}$, but with much increase in temperature, it decreases greatly [40]. In the case of A. gossypii, it is similar to housefly and shows the highest activity at $45{ }^{\circ} \mathrm{C}$. Temperature required for AChE maximum activity purified from B.dorsalis was estimated at $35{ }^{\circ} \mathrm{C}$. Of course, there are significant differences between 35 and $45{ }^{\circ} \mathrm{C}$, but with temperature increase up to $65^{\circ} \mathrm{C}$, enzyme activity decreases greatly [6].

$V_{\max }^{a p p}$ Values of compounds have decreased compared with the control situation and also, their $K_{m}{ }^{a p p}$ values have increased compared with control. These results indicate that inhibitory mechanisms of AChE by temephos compounds were mixed type. Among these compounds, compound 50 had the highest insecticidal effect and highest inhibitory potency on AChE, i.e high Ki. Thus, among this group of compounds, compound number 50 is a suitable model for designing of new compounds with insecticidal properties.

\subsection{QSAR analysis}

In equation 4 , the inhibitory potential has a great influence on electronic descriptors like $\mathrm{E}_{\mathrm{HO}}$ мо and $\mathrm{E}_{\mathrm{LUMO}}$ molecular orbital parameters. $\mathrm{E}_{\text {Hомо }}$ and $\mathrm{E}_{\mathrm{LUMO}}$ with a value of +14.961 and 11.798 are the most affected by inhibition parameter. Positive and negative sign shows that the two variables respectively increase and decrease the amount of $\mathrm{E}_{\mathrm{HOMO}}$ and $\mathrm{E}_{\mathrm{LUMO}}$ parameter 
combinations, and also increased the inhibition of compound. The last equation reveals that descriptor $\omega$, leaves the atom net charge and the net charge of phosphorus atom in order of importance with the inhibitory potential.

In table 8 , the regression coefficients are greater than 0.70 which is a sign of close relationship between the variables [19]. The result of correlation matrix of relationships showed that $\mathrm{E}_{\mathrm{HOMO}}$ have the greatest influence regression coefficient with inhibitory potential compared to other descriptors and the equation also expresses the highest interrelationships between this parameter and $\omega$ with $r=-0.61$ and the least interrelationships between this parameter and $Q_{N}$ with $r=-0.01$.

\subsection{Comparison of QSAR model of human with QSAR model of X. luteola on temephos deriva-} tives

Inhibitory potential of AChE of human on derivatives were studied. Result revealed that side aromatic substitutions links between $\mathrm{P}-\mathrm{N}, \mathrm{P}-\mathrm{O}$ and $\mathrm{P}-\mathrm{C}$, phenyl rings increases the combined inhibition of human acetylcholinesterase. The QSAR model of AChE of human denoted that independent variables $\mathrm{Q}_{(\mathrm{N} 1)}>\log _{\mathrm{P}}>E_{L U M O}>\mathrm{Q}_{(\mathrm{P} 1)}$ respectively have greatest inhibitory effect on the control of the human acetyl cholinesterase. Matrix relationship between $\log \mathrm{P}$ and $\mathrm{Q}(\mathrm{N} 1)$ with $\mathrm{r}=$ $-0 / 650$ shows that hydrophobicity properties of the molecules had great effect on the electronic properties; therefore they could have effect on inhibition of human AChE [19].

$\log \left(1 / \mathrm{IC}_{50}\right)=+0.175 \mu+0.845 Q_{P}+29.699 Q_{N}-12.903 E_{L U M O}-0.019 M v+27.921 \omega-0.124$ $n=10 ; R^{2}=0.922 ; S_{\text {reg }}=0.438 ; F_{\text {statistic }}=9.473$

But as cited in equations of pest $\mathrm{QSAR}$, parameter of $\mathrm{E}_{\mathrm{HOMO}}>\mathrm{E}_{\mathrm{LOMO}}>\omega>\mathrm{Q}_{\mathrm{X}}>\mathrm{Q}_{(\mathrm{p} 2)}$ respectively have the greatest effect on inhibition of AChE from elm leaf beetle and the highest interrelationships was between $\mathrm{E}_{\mathrm{HOMO}}$ and $\omega$. By comparing the two equations it could be concluded that a 
different variable of this class of phosphorus compounds has inhibition impact on AChE from human or insect. Primary efficacy variable of both equations is an electron property, and its impact on the human equation is dependent on structural features, but it is affected by other electronic features in the second equation. In another study involving the use of QSAR models on organ phosphorus, pesticides could be of help in synthesizing derivatives of this compound that have demonstrated better insecticidal properties. The equations of QSAR presented that electron descriptors have played a vital role on insecticidal effect. Compositions by this model was designed and tested in silicon. The results revealed that the insecticidal activity of newly synthesized compounds is greater than the existing insecticides [41]. Insecticidal effect of another class of derivatives was investigated on the AChE of housefly. This study was conducted on resistant strains of Musca domestica. The equation of the 36 combinations of PHA derivatives showed that the hydrophobic and electron orbitals properties are able to play a crucial role in the application of insecticidal activity on resistant strains [42]. These results established that the electronic features have more important insecticidal effect than any other descriptors in PHA derivatives compounds. It is therefore expected that with the change in the electron described, it could be design and the synthesis of PHA derivatives compounds are more favorable than the existent compound.

\section{Acknowledgements}

We gratefully acknowledge financial support from Iran National Science Grant No. 94000478. Also, University of Guilan and Tarbiat Modares University's Research Council are gratefully acknowledged.

\section{Reference}

[1] H.T. Wu, D.M. Li, B.W. Zhu, Y. Du, X.Q. Chai, Y. Murat, Characterization of acetylcholinesterase from the gut of sea cucumber, Stichopus japonicas, Fish Sci.79 (2013) 303-311. 
[2] B.B. Wang, F.C. Li, K.Z. Xu, M. Ni, J.S. Hu, J.H. Tian, Y.Y. Li, W.D. Shen, B. Li., Effects of mutations on the structure and function of silkworm type 1 acetylcholinesterase. Pestic. Biochem. Physiol. 89 (2015) 214-230.

[3] J. R. Gao, J.V. Rao, G.E. Wilde, K.Y. Zhu, Purification and kinetic analysis of acetylcholinesterase from western corn rootworm, Diabrotica virgifera (Coleoptera: Chrysomelidae), Arch. Insect Biochem. Physiol. 39 (1998) 118-125.

[4] F. Li, Z. Han, Purification and characterization of acetylcholinesterase from cotton aphid (Aphis gossypii Glover). Arch. Insect Biochem. Physiol. 51 (2002) 37-45.

[5] S.J. Yu, Insensitivity of acetylcholinesterase in a Weld strain of the fall armyworm, Spodoptera frugiperda (J. E. Smith), Pestic. Biochem. Physiol. 84 (2006) 135-142.

[6] Y.M. Hsiao, J.Y. Lai, H.Y. Liao, H.T. Feng, Purification and characterization of acetylcholinesterase from oriental fruit fly [Bactrocera dorsalis (Hendel)] (Diptera: Tephritidae), J. Agric. Food Chem. 52 (2004) 5340-5346.

[7] G.J. Lang, X.H. Zhang, M.Y. Zhang, C.X. Zhang, Comparison of catalytic properties and inhibition kinetics of two acetylcholinesterases from a lepidopteran insect, Pestic. Biochem. Physiol. 98 (2010) 175182.

[8] S. Oloff, R.B. Mailman, A. Trospha, Application of validated QSAR models of D1 dopaminergic antagonists for database mining, J. Med. Chem. 48 (2005)7322-7332.

[9] L. Santana, H. Uriarte, H. Gonzalez-Diaz, R. Zagotto, E. Soto-Otero, J. Mendez-Alvarez, A QSAR model for in silico screening of MAO-A inhibitors. Prediction, synthesis, and biological assay of novel coumarins, J. Med. Chem. 49 (2006) 1149-1156.

[10] P. Naik, K. Sindhura, T. Singh, H. Singh, Quantitative Structure -Activity Relationship (QSAR) for insecticides: Development of predictive in vivo insecticide activity models, SAR. QSAR. Environ. Res. 20 (2009) 551-566.

[11] Y. Mudasir, M. Wibowo, H.D. Pranowo, Design of new potent insecticides of organophosphate derivatives based on QSAR analysis, Indo. J. Chem. 13 (2013) 86 - 93.

[12] E. Bashari, M. Ghadamyari, J. Jalali Sendi, Toxicity, and biological and biochemical effects of hexaflumuron on the elm leaf beetle, Xanthogaleruca luteola (Col.: Chrysomelidae), J. Entomol. Soc. Iran. 34 (2014) 46-59.

[13] M.S. Chauhan, J.P. Shukla, U.K. Pandey, S. Bhadauria, Efficacy of some plant products as repellent to control Helicoverpa armigera (Hübner) (Lepidoptera: Noctuidae) fed on tomato (Lycopersicon esculentum), Int. J. Res. Bot. 3 (2013) 37-43.

[14] LeOra Software. POLO-PC, probit or logit analysis. Berkeley (CA), 1987. 
[15] G.L. Ellman, K.D. Courthey, V. Andres and R.M. Featherstone, A new and rapid colorimetric determination of acetylcholinesterase activity, Biochem. Pharmacol. 7 (1961) 88-95.

[16] M.M. Bradford, Rapid and sensitive method for the quantitation of microgram quantities of protein utilizing the principle of protein-dye binding, Anal. Biochem. 72 (1976) 248-254.

[17] E. Van Asperen, A study of housefly esterase by mean of a sensitive colorimetric method. J. Insect Physiol. 8 (1962) 401-416.

[18] M. Sharifi, M. Ghadamyari, K. Gholivand, A.A. Ebrahimi Valmoozi, M. Rajabi, Importance of physicochemical properties with help of QSAR for the design of new organophosphate as pesticide, Submitted.

[19] K. Gholivand, A.A. Ebrahimi Valmoozi, M. Bonsai, Synthesis and crystal structure of new temephos analogues as cholinesterase inhibitor: Molecular docking, QSAR study, and hydrogen bonding analysis of solid state, J. Agric. Food Chem. 62 (2014) 5761-5771.

[20] N. Pasteur, M. Raymond, F. Rosset, J.B. Berge, M. Amichot, D. Pauron, A. Cuany, D. Fournier, Cloning and detection of insecticide resistance genes. in: J.M. Crampton, et al. (Eds.), Molecular Biology of Insect Disease Vectors: A Methods Manual. Chapman and Hall, Cambridge, 1997, pp. 399-419.

[21] J.R. Gao, K.Y. Zhu, An acetylcholinesterase purified from the greenbug (Schizaphis graminum) with unique enzymological and pharmacological characteristics, Insect Biochem. Mol. Biol. 31 (2001) 10951104.

[22] M. Eisenthal, M. Danson, Enzyme Assays: A Practical Approach (Practical Approach Series), Second Ed., Oxford University Press, New York, 2002.

[23] SAS Institute (2002), SAS/GRAPH Software: Reference Volume 2 Version 8, Cary, NC: SAS Institute Inc.

[24] C. Hansch, T. Fujita. A Method for the correlation of biological activity and chemical structure, J. Am. Chem. Soc. 86 (1964) 1616-1626.

[25] SPSS Inc. (1999) SPSS for Windows, Version 9.0. SPSS Inc., Chicago, IL.

[26] G. Schuurmann, R.U. Ebert, J.W. Chen, B. Wang, R. Kuhne, External validation and prediction employing the predictive squared correlation coefficient — test set activity mean vs training set activity mean, J. Chem. Inf. Model. 48 (2008) 2140-2145.

[27] M.J. Frisch, G.W. Trucks, H.B. Schlegel, G.E. Scuseria, M.A. Robb, J.R. Cheeseman, J.A. Montgomery. Gaussian 03, Revision D.01, Gaussian, Inc., Wallingford CT. 2005. 
[28] D. Spassova, T. White, A.K. Singh, Acute effects of acephate and temephos on acetylcholinesterase activity, endocrine system and amino acid concentrations in rats, Comp. Biochem. Physiol. Part C, 126 (2000) 79-89.

[29] T.C. Sparks, Insecticide discovery: An evaluation and analysis, Pestic. Biochem. Physiol. 17 (2013) 8-17.

[30] S.F. Oppenheimer, organophosphates, serine esterase inhibition and modeling of organophosphate toxicity, J. Toxicol. Sci. 77 (2004) 185-197.

[31] A. L. Devonshire, G.D. Moores, A carboxylesterase with broad substrate specificity causes organophosphorus, carbamate and pyrethroid resistance in peach-potato aphids (Myzus persicae), Pestic. Biochem. Physiol. 18 (1982) 235-246.

[32] K.Y. Zhu, M.J. Clark, Purification and characterization of acetylcholinesterase from the Colorado potato beetle, Leptinotarsa decemlineata, Insect Biochem. Mol. Biol. 24 (1994) 453-461.

[33] S. Keane, M.F. Ryan, Purification, characterisation and inhibition by monoterpenes of acetylcholinesterase from the wax moth, Galleria mellonella (L.), Insect Biochem. Mol. Biol. 29 (2000) 1097-1104.

[34] C.E. Hwang, Y.H. Kim, D.H. Kwon, K.M. Seong, J.Y. Choi, H.Y. Je, S.H. Lee, Biochemical and toxicological properties of two acetylcholinesterases from the common bed bug, Cimex lectularius, Pestic. Biochem. Physiol. 110 (2014) 20-26.

[35] A.L. Gnagey, M. Forte, T.L. Rosenberry, Isolation and characterization of acetylcholinesterase from Drosophila, J. Biol. Chem. 262 (1987) 13290-13298.

[36] G. Xu, D.L. Bull, Acetylcholinesterase from the horn fly (Diptera: Muscidae) II: Biochemical and molecular properties, Arch. Insect Biochem. Physiol. 27 (1994) 109-121.

[37] K.Y. Zhu, J.M. Clark, Comparisons of kinetic properties of acetylcholinesterases purified from azinphosmethyl-susceptible and resistant strains of Colorado potato beetle, Pestic. Biochem. Physiol. 51 (1995) 57-67.

[38] R.N.C. Guedes, K.Y. Zhu, S. Kambhampati, B.A. Dover, An altered acetylcholinesterase conferring negative cross-insensitivity to different insecticidal inhibitors in organophosphate-resistant lesser grain borer, Rhyzopertha dominica, Pestic. Biochem. Physiol. 58 (1997) 55-62.

[39] R.N.C. Guedes, K.Y. Zhu, S. Kambhampati, B.A. Dover, Characterization of acetylcholinesterase purified from the lesser grain borer, Rhizopertha dominica (Coleoptera: Bostrichidae), Comp. Biochem. Physiol. 119 (1998) 205-210.

[40] D.J. Im, W.R. Kim, K.S. Boo, Purification and partial cDNA sequence of acetylcholinesterase from a Korean strain of the housefly, Musca domestica, J. Asia-Pacific Entomol. 7 (2004) 81-87.

[41] M. Mudasir, Y.M. Wibowo, H.D. Pranowo, Design of new insecticides of organophosphate derivatives based on QSAR analytical model, Indo. J. Chem. 5 (2016) 54-68. 
[42] V.K. Agrawal, S. Srivastava, P.V. Khadikar, QSAR study on phosphoramidothioate (Ace) toxicities in housefly, Mol. Divers. 8 (2004) 413-419. 


\begin{tabular}{ccccc}
\hline Compound & $\mathbf{1 9}$ & $\mathbf{3 0}$ & $\mathbf{3 2}$ & $\mathbf{5 0}$ \\
\hline $\mathbf{L C}_{\mathbf{5 0}}$ & 1423.047 & 1230.40 & 952.61 & 511.47 \\
(mg/l) (95\%confidence limit) & $(998.06-1858.05)$ & $(931.1-1663.2)$ & $(621.1-1015.4)$ & $(341.2-674.0)$ \\
Slope \pm Standard error & $1.24 \pm 0.41$ & $1.03 \pm 0.95$ & $1.55 \pm 0.25$ & $1.21 \pm 0.55$ \\
\hline
\end{tabular}
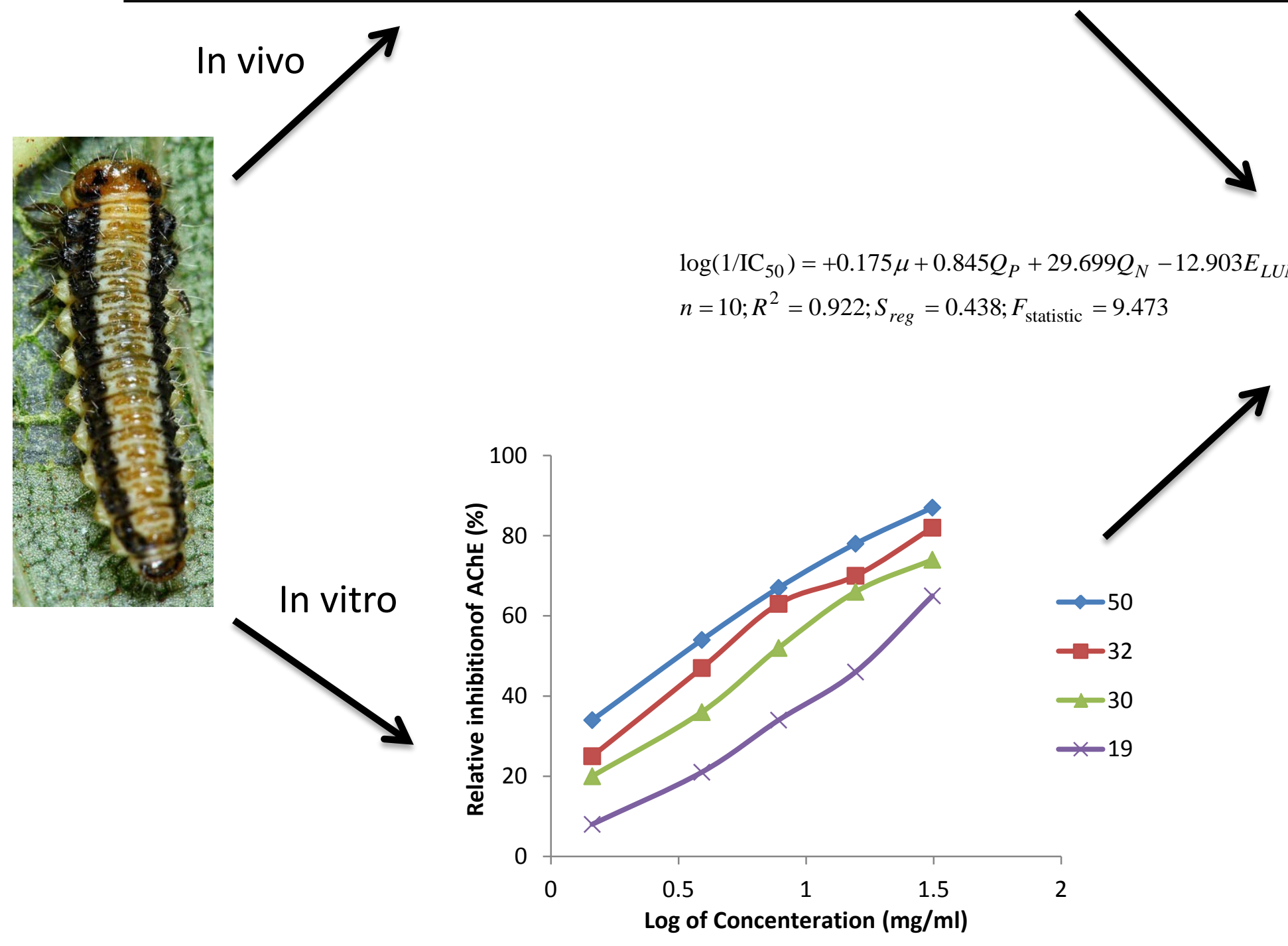